
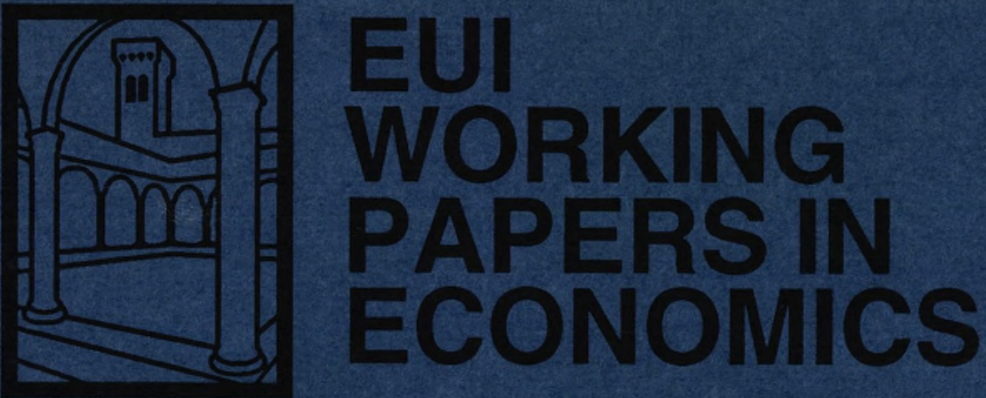

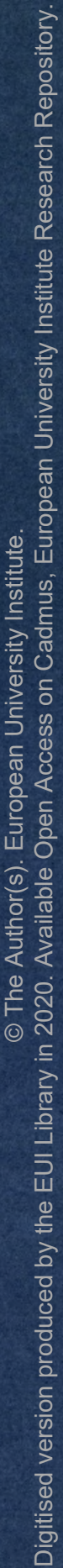


European University Library

|| ||||||||||||||||||||||||||||||||||||||||||||||||||||||||||||||||||||||||||

30001001588021 
EUROPEAN UNIVERSITY INSTITUTE, FLORENCE

ECONOMICS DEPARTMENT

EUI Working Paper ECO No. 94/20

La Pléiade and Exchange Rate Pass-Through

ANDRZEJ BANIAK

and

LOUIS PHLIPS 
All rights reserved.

No part of this paper may be reproduced in any form without permission of the authors.

(C) Andrzej Baniak and Louis Phlips

Printed in Italy in May 1994

European University Institute

Badia Fiesolana

I - 50016 San Domenico (FI)

Italy 


\title{
La Pléiade and Exchange Rate Pass-Through*
}

\author{
Andrzej Baniak ${ }^{\dagger}$ and Louis Phlips ${ }^{\ddagger}$
}

March 1994

\begin{abstract}
We examine the effects of a change in the exchange rate on sales and prices in the framework of a two-country, two-commodity duopoly model with joint production. We distinguish two kinds of reaction. When the firm located in the country whose currency depreciates (appreciates) increases (decreases) sales in both countries, we call it the "firm specific" effect. If all sales in the country which appreciates (depreciates) its currency increase (decrease), we call it the "country specific" effect. Strategic substitutability, economies of joint production and/or economies of scale lead to the firm specific effect. Strategic complementarity, diseconomies of joint production and/or diseconomies of scale lead to the country specific effect.
\end{abstract}

${ }^{*}$ We would like to thank Berthold Herrendorf, Curtis Eberwein and Robert Waldmann for helpful comments. Of course, we are responsible for all views expressed and any errors.

†European University Institute, Florence, Oskar Lange Academy of Economics, Wroclaw, Poland and International Centre for Economic Research, Torino, Italy.

${ }^{\ddagger}$ European University Institute, Florence. 


\section{Introduction}

The model to be presented in this paper is motivated by the press announcement that the French publishing house Gallimard is putting out an "Italian Pléiade". Every cultivated person supposedly knows "La Pléiade", Gallimard's French high quality edition of the collected works of famous novelists. The "Italian Pléiade" includes Italian translations and competes directly with a collection of comparable quality by the Italian publishing house Mondadori. Gallimard's initiative came at a time when the Italian lira was going through a series of devaluations.

This fait divers served as a guide to our analysis of exchange rate pass-through. Here are two markets: the French market $(x)$ and the Italian market $(y)$. In each market there are two sellers: Gallimard (player $g$ ) and Mondadori (player $m$ ). The two markets are treated as separated: to travel from Italy to France or vice-versa is expensive for a buyer who wants to buy one of these books, so that prices can differ between markets; in addition, the distribution systems are separated by exclusive dealing ${ }^{1}$.

Mondadori sells its collection in both markets. Gallimard sells its two collections in both markets. Suppose, to simplify the analysis, that Mondadori's product is a perfect substitute for Gallimard's Italian Pléiade. Then we have two products on each market: the French Pléiade (product $a$ ) and the Italian translations (product $b$ ). These two products could be complements (for language teachers and students) or substitutes (for general readers who are fluent in both French and Italian). They could also be independent (for buyers who read only in one of the two languages).

Product $a$ (the French Pléiade) is sold by one producer only (Gallimard) in both markets. However, product $b$ (the Italian translation)is sold by the two producers in both markets.

The question to be answered is: how does a depreciation of the

\footnotetext{
${ }^{1}$ We ignore the occasional arbitrage telephone call from an Italian language teacher to a friend in Paris asking him or her to buy there at a lower price and send by mail.
} 
lira affect the sales and the prices of the products in Italy and in France respectively? We will show that Mondadori will sell more in both countries and that Gallimard, to the contrary, will loose sales of its two products in both markets whether the two products are substitutes, complements or independent (from the consumers' point of view), on one condition: both producers should consider their product(s) as "strategic substitutes". Strategic substitutability occurs when it is in a firm's interest to react to an increase of the competitor's sales by a decrease of its own sales and vice-versa. To the contrary, when it is in their interest to react to an "aggressive" sales policy by an increase in sales (this is called "strategic complementarity"), then both Mondadori and Gallimard will increase sales in France and decrease sales in Italy, whether the products $a$ and $b$ are substitutes, complements or independent. Whether a good is considered a strategic substitute or a strategic complement by a player depends on this player's market share and on the curvature of the demand function.

Strategic substitutability and complementarity thus play a crucial role. Strategic substitutability leads to increased sales in both countries for the firm located in the country whose currency depreciates. We will call this the firm specific effect. Strategic complementarity leads to increased sales in the country that appreciates and to decreased sales in the country that devalues for both firms. We will call this the country specific effect.

The normal price reaction is for prices to decrease in the country that appreciates and to increase in the country that devalues. When the relationships between two commodities (on the demand side and/or the cost side) are taken into account, as we do in our model, other price reactions can appear. We will show that if products $a$ and $b$ are independent on the demand side, the price of $a$ can go $u p$ in both countries, under certain cost conditions (economies of scale or of joint production for Gallimard) and strategic substitutability. This is a surprising result, at first sight. Yet, it is a straightforward consequence of the fact that Gallimard is then a price discriminating monopolist.

Our model uses unspecified demand functions, and is thus more 
general than the approach followed by Martin and Phlips (1994) who consider a duopoly model with differentiated products but operate in a linear framework. We build on the papers by Hens, Kirman and Phlips (1991) and Kirman and Phlips (1992) who use general demand and cost functions but consider only one homogeneous good in each market. The points where we extend their results will be indicated as we proceed.

Section 2 presents the model, introduces the concepts of strategic substitutes and complements and the a priori restrictions imposed for comparative statics. In section 3 , the effects of an appreciation on quantities and prices are analyzed under the assumption that there is no strategic interaction between duopolists. Section 4 allows for economies and diseconomies of joint production. We show that economies of joint production connected with strategic substitutability lead to the firm specific effect. In section 5 the effects of economies of scale are analyzed. The appendix gives the proofs of the propositions.

\section{The Model}

There are two countries (markets) $x$ and $y$ which are separated in the sense that demands in one country are independent of the prices in the other country. The duopolistic structure is as follows: there is a one firm $g$ which is located in country $x$, and one firm $m$ located in country $y$. There are two products: $a$ and $b$ which can be independent, imperfect substitutes or complements. Firm $g$ produces both products; firm $m$ produces only $b$. Product $b$ is homogeneous. Both products are sold in both countries. To suppose that only one of the duopolists produces the two goods makes the model tractable without loss of generality.

The inverse demand function for good $a$ in country $x$ is

$$
p_{a x}=p_{a x}\left(x_{a}, x_{b}^{g}+x_{b}^{m}\right)
$$

where $x_{a}$ is the quantity of good $a$ produced by firm $g$ and sold in country $x, x_{b}^{g}$ is the quantity of good $b$ produced by firm $g$ and sold in country $x$ and $x_{b}^{m}$ is the quantity of good $b$ produced by firm $m$ and sold in country 
$x$. Let $x_{b}=x_{b}^{g}+x_{b}^{m}$ be the total quantity of good $b$ sold in country $x$. We assume that $\partial p_{a x} / \partial x_{a}=p_{a x}^{1}<0$ and, if goods $a$ and $b$ are substitutes (complements), then $\partial p_{a x} / \partial x_{b}=p_{a x}^{2}<(>) 0$.

We can define other inverse demand functions in a similar way:

- for good $b$ in country $x$ :

$$
p_{b x}=p_{b x}\left(x_{a}, x_{b}\right),
$$

where $p_{b x}^{2}<0$ and if goods are substitutes (complements) then $p_{b x}^{1}<(>) 0$.

- for good $a$ in country $y$ :

$$
p_{a y}=p_{a y}\left(y_{a}, y_{b}^{g}+y_{b}^{m}\right)=p_{a y}\left(y_{a}, y_{b}\right)
$$

where $y_{a}, y_{b}^{g}, y_{b}^{m}$ are quantities sold in country $y$ and $y_{b}=y_{b}^{g}+y_{b}^{m}$,

- for good $b$ in country $y$ :

$$
p_{b y}=p_{b y}\left(y_{a}, y_{b}\right)
$$

We assume that the inverse demand functions are twice continuously differentiable. Analogous assumptions about the signs of partial derivatives (as in the first two inverse demand functions) are imposed.

The cost function for firm $g$ is

$$
c_{g}=c_{g}\left(x_{a}+y_{a}, x_{b}^{g}+y_{b}^{g}\right)
$$

and for firm $m$ :

$$
c_{m}=c_{m}\left(x_{b}^{m}+y_{b}^{m}\right) .
$$

The above formulation of the cost functions is somewhat restrictive: it reduces the concept of economies of scope to one of economies of scale.

It is assumed that cost functions are twice continuously differentiable and that marginal costs are positive. We will say that both firms exhibit economies (diseconomies) of scale if

$$
c_{g}^{11}, c_{g}^{22}, c_{m}^{\prime \prime}<(>) 0 .
$$


The firm $g$ exhibits economies (diseconomies) of joint production if the cross-partial derivative $c_{g}^{12}$ is negative (positive).

The exchange rate $e$ is defined as the value of the currency of country $x$ (French francs) expressed in the currency of country $y$ (Italian lira).

Thus, firm $g$ earns profits

$$
\Pi_{g}=\Pi_{g}\left(x_{a}, x_{b}^{g}, x_{b}^{m}, y_{a}, y_{b}^{g}, y_{b}^{m}\right)=p_{a x} x_{a}+p_{b x} x_{b}^{g}+(1 / e)\left(p_{a y} y_{a}+p_{b y} y_{b}^{g}\right)-c_{g},
$$

in the currency of country $x$ while firm $m$ earns

$$
\Pi_{m}=\Pi_{m}\left(x_{a}, x_{b}^{g}, x_{b}^{m}, y_{a}, y_{b}^{g}, y_{b}^{m}\right)=e p_{b x} x_{b}^{m}+p_{b y} y_{b}^{m}-c_{m}
$$

in the currency of country $y$.

Thus, there are six first-order conditions that must be satisfied in the interior Nash equilibrium:

$$
\begin{aligned}
\Pi_{g}^{1} & =p_{a x}^{1} x_{a}+p_{a x}+p_{b x}^{1} x_{b}^{g}-c_{g}^{1}=0 \\
\Pi_{g}^{2} & =p_{a x}^{2} x_{a}+p_{b x}+p_{b x}^{2} x_{b}^{g}-c_{g}^{2}=0 \\
\Pi_{m}^{3} & =e\left(p_{b x}^{2} x_{b}^{m}+p_{b x}\right)-c_{m}^{\prime}=0 \\
\Pi_{g}^{4} & =(1 / e)\left(p_{a y}^{1} y_{a}+p_{a y}+p_{b y}^{1} y_{b}^{g}\right)-c_{g}^{1}=0 \\
\Pi_{g}^{5} & =(1 / e)\left(p_{a y}^{2} y_{a}+p_{b y}+p_{b y}^{2} y_{b}^{g}\right)-c_{g}^{2}=0 \\
\Pi_{m}^{6} & =p_{b y}^{2} y_{b}^{m}+p_{b y}-c_{m}^{\prime}=0
\end{aligned}
$$

The first three equations refer to country $x$, the last three to country $y$.

We are interested in how the equilibrium given by the system of equations (10)-(15) reacts to an exogenous exchange rate change. Generally speaking, the increase of $e$ has two direct effects. That is to say, firm $g$ located in country $x$ whose currency appreciates decreases sales of its two products in country $y: d y_{a} / d e<0, d y_{b}^{g} / d e<0$, and firm $m$ located in country $y$ which depreciates its currency increases sales of product $b$ in country $x: d x_{b}^{m} / d e>0$. 
Then we can distinguish two further effects, that is to say, the changes of sales of both firms on their domestic markets.

A first possibility is that firm $m$ sells more in its domestic market $y$, whereas firm $g$ decreases sales in its domestic market $x$. In this case, firm $m$, located in the country $y$ which depreciates its currency, sells more of its product in both countries:

$$
\frac{d x_{b}^{m}}{d e}>0, \quad \frac{d y_{b}^{m}}{d e}>0 .
$$

The second duopolist, firm $g$, from the country $x$ which appreciates its currency, decreases sales of its two products in both countries

$$
\frac{d x_{a}}{d e}<0, \quad \frac{d x_{b}^{g}}{d e}<0, \quad \frac{d y_{a}}{d e}<0, \quad \frac{d y_{b}^{g}}{d e}<0 .
$$

We will call such a response to the change of the exchange rate the firm specific effect.

A second possibility is for firm $m$ to sell less in domestic market $y$, while firm $g$ increases sales in domestic market $x$. Then, the sales of all products increase in the country which appreciates its currency

$$
\frac{d x_{a}}{d e}>0, \quad \frac{d x_{b}^{g}}{d e}>0, \quad \frac{d x_{b}^{m}}{d e}>0,
$$

and all sales in the country which depreciates its currency decrease

$$
\frac{d y_{a}}{d e}<0, \quad \frac{d y_{b}^{g}}{d e}<0, \quad \frac{d y_{b}^{m}}{d e}<0 .
$$

We will name such a reaction the country specific effect.

The way a change in $e$ affects prices depends on aspects of both countries' market and production structures. To study the problem more thoroughly we introduce the concepts of strategic substitutes and complements.

\subsection{Strategic Substitutes and Complements}

This terminology was introduced by Bulow, Geanakoplos and Klemperer (1985). Strategic substitutes and complements are defined by whether 
a more "aggressive" strategy by one duopolist lowers or raises the other duopolist's marginal profits.

Firm $g$ regards commodity $b$ as a strategic substitute in market $x$ when

$$
\frac{\partial^{2} \Pi_{g}}{\partial x_{b}^{m} \partial x_{b}^{g}}=\Pi_{g}^{23}<0 .
$$

In other words: an increase in firm $m$ 's sales reduces the marginal profitability of firm $g$. Conversely: firm $g$ regards commodity $b$ as a strategic complement when the cross-partial derivative in equation (20) is positive.

The concept of strategic substitutes and complements has an interesting interpretation when the duopolists compete in one market. In this case the slope of the reaction function for firm $g$ is given by

$$
-\frac{\partial^{2} \Pi_{g}}{\partial x_{b}^{m} \partial x_{b}^{g}} / \frac{\partial^{2} \Pi_{g}}{\partial x_{b}^{g 2}}=-\frac{\Pi_{g}^{23}}{\Pi_{g}^{22}} .
$$

Under the assumption of strict concavity of the profit function, the denominator in equation (21) is negative. Hence, if $\operatorname{good} b$ is a strategic substitute (complement) for firm $g$ then the reaction function is downward sloping (upward sloping). We can interpret this in another way. Good $b$ is a strategic substitute (complement) for firm $g$ if the optimal response to a more aggressive strategy (increase of sales) of firm $m$ is to decrease (increase) sales.

In our model we have two commodities in every market. Hence we can distinguish different kinds of strategic substitutability or complementarity. Equation (20) gives the usual definition. In a differentiated market where goods $a$ and $b$ are imperfect substitutes, we can define a new concept involving the two goods. We will say that firm $g$ considers commodity $a$ as a strategic substitute (complement) to $b$ in market $x$ if

$$
\frac{\partial^{2} \Pi_{g}}{\partial x_{b}^{m} \partial x_{a}}=\Pi_{g}^{13}<(>) 0
$$

The situation of $m$ is different because it produces only one commodity and faces two possible strategic actions by firm $g$ : through a change of quantity in product $a$ or product $b$. 
Thus, we can say in the usual way that firm $m$ regards commodity $b$ as a strategic substitute (complement) in country $x$ if

$$
\frac{\partial^{2} \Pi_{m}}{\partial x_{b}^{g} \partial x_{b}^{m}}=\Pi_{m}^{32}<(>) 0 .
$$

By analogy with (22), we will say that firm $m$ regards commodity $b$ as a strategic substitute (complement) to $a$ in country $x$ if

$$
\frac{\partial^{2} \Pi_{m}}{\partial x_{a} \partial x_{b}^{m}}=\Pi_{m}^{31}<(>) 0 .
$$

Similar definitions apply to market $y$. Note that in a linear framework, if products $a$ and $b$ are substitutes (complements) on the demand side, then they are treated as a strategic substitutes (complements) by both producers. Thus, demand and strategic substitutability (complementarity) coincide.

If products are independent i.e. the price of commodity $b$ does not depend on the sales of commodity $a$ and vice versa then the inverse demand functions reduce to

$$
p_{a x}=p_{a x}\left(x_{a}\right), \quad p_{b x}=p_{b x}\left(x_{b}\right) \quad p_{a y}=p_{a y}\left(y_{a}\right), \quad p_{b y}=p_{b y}\left(y_{b}\right),
$$

and $\Pi_{m}^{31}=\Pi_{g}^{13}=0$. In other words, there is no strategic interaction between $a$ and $b$. The concept of strategic substitutability and complementarity hence applies only to commodity $b$ since $a$ is produced by $g$ only. In this case a strategic interaction has an interesting interpretation for good $b$. From equations (11) and (12) we have

$$
\Pi_{g}^{23}=p_{b x}^{\prime}+p_{b x}^{\prime \prime} x_{b}^{g} \quad \text { and } \quad \Pi_{m}^{32}=p_{b x}^{\prime}+p_{b x}^{\prime \prime} x_{b}^{m} .
$$

Let $\alpha=x_{b}^{g} / x_{b}$ denote the share of firm $g$ 's sales in total sales. Then (26) becomes

$$
\Pi_{g}^{23}=\alpha p_{b x}^{\prime}\left(\frac{1}{\alpha}+\frac{p_{b x}^{\prime \prime} x_{b}}{p_{b x}^{\prime}}\right) \text { and } \Pi_{m}^{32}=(1-\alpha) p_{b x}^{\prime}\left(\frac{1}{1-\alpha}+\frac{p_{b x}^{\prime \prime} x_{b}}{p_{b x}^{\prime}}\right) .
$$

Thus, firm $g$ regards $b$ as a strategic substitute (complement) if the sign of the expression

$$
\frac{1}{\alpha}+\frac{p_{b x}^{\prime \prime} x_{b}}{p_{b x}^{\prime}}
$$


is positive (negative) ${ }^{2}$. The first term in (28) shows how market share affects strategic interaction. This effect is always positive. The second term in (28) measures the curvature of the inverse demand function. More precisely, it is the elasticity of inverse marginal demand $p_{b x}^{\prime}$, which shows the influence of demand on strategic interaction. If the demand function $p_{b x}$ is concave (linear) then $p_{b x}^{\prime \prime} x_{b} / p_{b x}^{\prime}$ is positive (zero) and we have strategic substitutability. When $p_{b x}$ is convex, strategic complementarity can occur. The larger is firm g's market share (i.e. the higher is $\alpha$ ), or the more "curved" is $p_{b x}$, the more likely is strategic complementarity.

If one firm (say $g$ ) regards $b$ as a strategic complement and the other one $(m)$ regards $b$ as a strategic substitute then

$$
\frac{1}{\alpha}+\frac{p_{b x}^{\prime \prime} x_{b}}{p_{b x}^{\prime}}<0 \text { and } \frac{1}{1-\alpha}+\frac{p_{b x}^{\prime \prime} x_{b}}{p_{b x}^{\prime}}>0 .
$$

From (29), we get $\alpha>1 / 2$. For this reason, a firm that treats product $b$ as a strategic complement (substitute) must have a higher (lower) market share and therefore an upward (downward) sloping reaction function ${ }^{3}$.

The cross-partial derivative $\Pi_{g}^{12}$ refers only to firm $g$ 's behaviour. It measures the change of the marginal profit from sales of one product when firm $g$ increases sales of a second product and is equal to

$$
\left(p_{a x}^{12} x_{a}+p_{a x}^{2}+p_{b x}^{21} x_{b}^{g}+p_{b x}^{1}\right)-c_{g}^{12} .
$$

The first term in (30) shows how demand affects $\Pi_{g}^{12}$. If the cross-partial derivatives $p_{a x}^{12}$ and $p_{b x}^{21}$ are small, they do not affect the sign of (30). This sign is then determined by the sum $p_{a x}^{2}+p_{b x}^{1}$ which measures the

\footnotetext{
${ }^{2}$ Expression (28) can be helpful in the empirical identification of strategic interaction. One would need to have data on market shares and to estimate the curvature of the demand functions.

${ }^{3}$ The same conclusion was obtained by Bulow et al.(1985), p.500.

Another example of a situation where one reaction curve is upward sloping and the other is downward sloping is connected with mixed duopoly: one duopolist is a labour-managed firm which maximizes profit per worker, the second duopolist is a profit maximizer. In this case the labour-managed firm has an upward sloping reaction curve and the profit maximizing firm has a downward sloping reaction curve (see Delbono, Rossini (1992)).
} 
degree of product differentiation. Roughly speaking: the higher is the degree of substitutability (complementarity) of products, the more likely $\Pi_{g}^{12}$ is negative (positive). The second term in (30) measures the degree of economies of joint production. We can conclude that economies of joint production and product complementarity require $\Pi_{g}^{12}$ to be positive. Conversely, if $g$ has diseconomies of joint production and products are substitutes, then $\Pi_{g}^{12}$ is negative. Note that if the goods are independent on the demand side, then $\Pi_{g}^{12}=-c_{g}^{12}$ and the whole conception is reduced to (dis)economies of joint production.

The cross-partial derivative $\Pi_{g}^{12}$ can also be interpreted in another way. Taking the partial derivative of the first-order condition (10) with respect to $x_{b}^{g}$ and totally differentiating the result, we obtain

$$
\frac{d x_{a}}{d x_{b}^{g}}=-\frac{\Pi_{g}^{12}}{\Pi_{g}^{11}} .
$$

We see that, under the assumption of strict concavity of the profit function, the sign of $d x_{a} / d x_{b}^{g}$ is equal to the sign of $\Pi_{g}^{12}$. Hence, if firm $g$ increases the sales of good $b$ in market $x$, it will also increase the sales of $a$ in $x$, when $\Pi_{g}^{12}>0$. Conversely, when $\Pi_{g}^{12}<0$, it is in $g$ 's interest to decrease the sales of good $a$, whenever the sales of good $b$ have increased.

\subsection{Second-order and Stability Conditions}

To examine the effect of a change of the exchange rate, we totally differentiate the first-order conditions to obtain a system of six equations which can be written in matrix form

$$
\left[\begin{array}{cccccc}
\Pi_{g}^{11} & \Pi_{g}^{12} & \Pi_{g}^{13} & -c_{g}^{11} & -c_{g}^{12} & 0 \\
\Pi_{g}^{21} & \Pi_{g}^{22} & \Pi_{g}^{23} & -c_{g}^{21} & -c_{g}^{22} & 0 \\
\Pi_{m}^{31} & \Pi_{m}^{32} & \Pi_{m}^{33} & 0 & 0 & -c_{m}^{\prime \prime} \\
-c_{g}^{11} & -c_{g}^{21} & 0 & \Pi_{g}^{44} & \Pi_{g}^{45} & \Pi_{g}^{46} \\
-c_{g}^{12} & -c_{g}^{22} & 0 & \Pi_{g}^{54} & \Pi_{g}^{55} & \Pi_{g}^{56} \\
0 & 0 & -c_{m}^{\prime \prime} & \Pi_{m}^{64} & \Pi_{m}^{65} & \Pi_{m}^{66}
\end{array}\right]\left[\begin{array}{c}
d x_{a} \\
d x_{b}^{g} \\
d x_{b}^{m} \\
d y_{a} \\
d y_{b}^{g} \\
d y_{b}^{m}
\end{array}\right]=\left[\begin{array}{c}
0 \\
0 \\
K \\
L \\
M \\
0
\end{array}\right] d e
$$


where

$$
\begin{aligned}
K & =-\frac{\partial \Pi_{m}^{3}}{\partial e}=-\left(p_{b x}^{2} x_{b}^{m}+p_{b x}\right) \\
L & =-\frac{\partial \Pi_{g}^{4}}{\partial e}=\left(1 / e^{2}\right)\left(p_{a y}^{1} y_{a}+p_{a y}+p_{b y}^{1} y_{b}^{g}\right) \\
M & =-\frac{\partial \Pi_{g}^{5}}{\partial e}=\left(1 / e^{2}\right)\left(p_{a y}^{2} y_{a}+p_{b y}+p_{b y}^{2} y_{b}^{g}\right) .
\end{aligned}
$$

From (12)-(14) we get

$$
\begin{aligned}
K & =-(1 / e) c_{m}^{\prime}<0 \\
L & =(1 / e) c_{g}^{1}>0 \\
M & =(1 / e) c_{g}^{2}>0 .
\end{aligned}
$$

We will refer to the matrix of sixth order from equation (32) as matrix $A=\left[a_{i j}\right]$. It can be decomposed into four quadratic matrices of the third order:

$$
A=\left[\begin{array}{ll}
A_{1} & A_{3} \\
A_{3} & A_{2}
\end{array}\right]
$$

It is assumed that matrix $A$ is negative definite, which in particular implies that

- the Nash equilibrium is locally strictly stable,

- the trace of $A$ is negative, which implies that the second-order conditions are satisfied,

- in the absence of market $x$, market $y$ would be strictly stable and vice versa, hence $\operatorname{det} A_{1}<0$ and $\operatorname{det} A_{2}<0$,

- the market for product $b$ is strictly stable in both countries i. e.

$$
\left|\begin{array}{ll}
a_{22} & a_{23} \\
a_{32} & a_{33}
\end{array}\right|>0 \text { and }\left|\begin{array}{ll}
a_{55} & a_{56} \\
a_{65} & a_{66}
\end{array}\right|>0 .
$$




\section{No strategic interaction}

We first investigate the case in which strategic interaction can be neglected i.e. $\Pi_{g}^{13}=\Pi_{g}^{23}=\Pi_{m}^{31}=\Pi_{m}^{32}=\Pi_{g}^{46}=\Pi_{g}^{56}=\Pi_{m}^{64}=\Pi_{m}^{65}$ are equal to zero ${ }^{4}$ (or arbitrarily small). Matrix $\mathrm{A}$ is then

$$
\left[\begin{array}{cccccc}
\Pi_{g}^{11} & \Pi_{g}^{12} & 0 & -c_{g}^{11} & -c_{g}^{12} & 0 \\
\Pi_{g}^{21} & \Pi_{g}^{22} & 0 & -c_{g}^{21} & -c_{g}^{22} & 0 \\
0 & 0 & \Pi_{m}^{33} & 0 & 0 & -c_{m}^{\prime \prime} \\
-c_{g}^{11} & -c_{g}^{21} & 0 & \Pi_{g}^{44} & \Pi_{g}^{45} & 0 \\
-c_{g}^{12} & -c_{g}^{22} & 0 & \Pi_{g}^{54} & \Pi_{g}^{55} & 0 \\
0 & 0 & -c_{m}^{\prime \prime} & 0 & 0 & \Pi_{m}^{66}
\end{array}\right]
$$

and we can decompose the comparative statics system (32) into two systems:

- for firm $m$ :

$$
\left[\begin{array}{cc}
\Pi_{m}^{33} & -c_{m}^{\prime \prime} \\
-c_{m}^{\prime \prime} & \Pi_{m}^{66}
\end{array}\right]\left[\begin{array}{l}
d x_{b}^{m} \\
d y_{b}^{m}
\end{array}\right]=\left[\begin{array}{c}
K \\
0
\end{array}\right] d e
$$

${ }^{4}$ If moreover products are independent, then from $\Pi_{g}^{23}=\Pi_{m}^{32}=0$ and (26) we have $x_{b}^{g}=x_{b}^{m}$. Firms thus share total sales equally and $\alpha=1 / 2$. From (27) we get

$$
\frac{p_{b x}^{\prime \prime} x_{b}}{p_{b x}^{\prime}}=-2
$$

By solving the above equation one gets $p_{b x}=A+\left(B / x_{b}\right)$ where $A$ and $B$ are parameters. The assumption about negligible strategic interaction leads therefore to a specific form of the demand function. 
- and for firm $g$ :

$$
\left[\begin{array}{cccc}
\Pi_{g}^{11} & \Pi_{g}^{12} & -c_{g}^{11} & -c_{g}^{12} \\
\Pi_{g}^{21} & \Pi_{g}^{22} & -c_{g}^{21} & -c_{g}^{22} \\
-c_{g}^{11} & -c_{g}^{21} & \Pi_{g}^{44} & \Pi_{g}^{45} \\
-c_{g}^{12} & -c_{g}^{22} & \Pi_{g}^{54} & \Pi_{g}^{55}
\end{array}\right]\left[\begin{array}{c}
d x_{a} \\
d x_{b}^{g} \\
d y_{a} \\
d y_{b}^{g}
\end{array}\right]=\left[\begin{array}{c}
0 \\
0 \\
L \\
M
\end{array}\right] d e
$$

Both firms are therefore independent. Moreover, they adjust to the exogenous movement of the exchange rate like monopolists ${ }^{5}$. Firm $m$ acts as a monopolist that discriminates across markets. Firm $g$ acts as a monopolist that must consider the effects of joint production when discriminating between markets. We start with firm $m$.

Proposition 1 If strategic interaction can be neglected, then after a depreciation of the currency of country y firm $m$ will sell more in foreign country $x$. The change of sales in its domestic market $y$ depends on economies of scale. If firm $m$ has economies (diseconomies) of scale then it will increase (decrease) sales in country $y$.

PROOF Solving (42) one gets

$$
\operatorname{sign}\left(d x_{b}^{m} / d e\right)=\operatorname{sign} K \Pi_{m}^{66}=+
$$

and

$$
\operatorname{sign}\left(d y_{b}^{m} / d e\right)=\operatorname{sign} K c_{m}^{\prime \prime}=-\operatorname{sign} c_{m}^{\prime \prime}
$$

The higher marginal revenue in foreign market $x$ pushes firm $m$ to increase sales in country $x$. That leads to the decrease (increase) of marginal costs if firm $m$ has economies (diseconomies) of scale. In order to equalize marginal revenue with marginal costs in market $y$, firm $m$ has to increase (decrease) sales in country $y$.

For firm $g$ we obtain propositions 2 and 3 .

\footnotetext{
${ }^{5}$ If both firms were monopolists, they would have first-order conditions different from equations (10)-(15), but it is easy to show that the comparative statics would be the same as in (42) and (43).
} 
Proposition 2 If strategic interaction can be neglected and products a and $b$ are independent then after the depreciation of the currency of country y firm $g$ will decrease sales of its two products in both countries if it has economies of scale i.e. $c_{g}^{11}, c_{g}^{22}<0$ and economies of joint production i.e. $c_{g}^{12}<0$.

\section{PROOF see Appendix}

Proposition 3 If strategic interaction can be neglected and products a and $b$ are differentiated, then after a depreciation of the currency of country $y$ :

(1) if $\Pi_{g}^{12}, \Pi_{g}^{45}>0$ and one of two conditions is satisfied

(a) at least one of the cost factors can be neglected i.e. $c_{g}^{12}=$ 0 or $c_{g}^{22}=c_{g}^{11}=0$ or,

(b) both cost factors work in the same direction i.e. $c_{g}^{12} c_{g}^{11}>$ 0 and $c_{g}^{12} c_{g}^{22}>0$

then firm $g$ will sell less of its two products in foreign country $y$.

(2) If firm $g$ has economies of scale or economies of joint production or both and $\Pi_{g}^{12}, \Pi_{g}^{45}>0$, then firm $g$ will reduce sales of its two products in its domestic country $x$.

(3) If firm $g$ has diseconomies of scale or diseconomies of joint production and $\Pi_{g}^{12}, \Pi_{g}^{45}>0$, then firm $g$ will increase sales of its two products in its domestic country $x$.

\section{PROOF see Appendix.}

The fall of demand in the foreign market $y$ forces firm $g$ to a reduction of the sales of its two products in market $y$. That leads to an increase (decrease) of marginal costs if firm $g$ has economies of joint production and/or economies of scale (diseconomies of joint production and/or diseconomies of scale). Firm $g$ then reoptimizes in market $x$ by adjusting marginal revenues to marginal costs and by reducing (raising) sales in market $x$ if marginal costs have increased (decreased). 
We can conclude that in absence of strategic substitutability and complementarity, economies of joint production and/or economies of scale lead to the firm specific reaction. On the other hand, one can expect the country specific reaction when the duopolists have diseconomies of scale and/or diseconomies of joint production.

\section{The effects of economies of joint produc- tion}

Consider the situation where the markets are only linked by economies of joint production for firm $g$ i.e. $c_{g}^{12} \neq 0$. There are no economies of scale: $c_{g}^{11}=c_{g}^{22}=c_{m}^{\prime \prime}=0$. We start with the general situation where products $a$ and $b$ are imperfect substitutes or complements.

Proposition 4 If there are no economies of scale then after an appreciation of the currency of country $x$

(1) one can expect the firm specific effect if firm $g$ has economies of joint production, i.e. $c_{g}^{12}<0$, and both firms regard both goods as strategic substitutes in both markets, i.e. $\Pi_{g}^{13}, \Pi_{g}^{23}, \Pi_{m}^{31}, \Pi_{m}^{32}, \Pi_{g}^{46}, \Pi_{g}^{56}, \Pi_{m}^{64}, \Pi_{m}^{65}<0$ and $\Pi_{g}^{12}, \Pi_{g}^{45}>0$,

(2) one can expect the country specific effect if firm $g$ has diseconomies of joint production, i.e. $c_{g}^{12}>0$, and both firms regard both goods as strategic complements in both markets, i.e. $\Pi_{g}^{13}, \Pi_{g}^{23}, \Pi_{m}^{31}, \Pi_{m}^{32}, \Pi_{g}^{46}, \Pi_{g}^{56}, \Pi_{m}^{64}, \Pi_{m}^{65}>0$ and $\Pi_{g}^{12}, \Pi_{g}^{45}>0$.

PROOF see Appendix.

The explanation is as follows. Firm $g$ reduces sales of its two goods in its foreign market $y$. Hence, by economies of joint production, (see proposition 3(2)) firm $g$ has an incentive to sell less of good $a$ in its domestic market $x$ (because its sales of $b$ went down in market $y$ ), and to reduce sales of good $b$ in market $x$ (because it reduces sales of $a$ abroad). 
In domestic market $x$ firm $g$ faces higher sales of good $b$ by firm $m$. Hence, the strategic substitutability assumption pushes firm $g$ to a reduction of the sales of its two products in market $x$ (remember that strategic substitutability means that the optimal response to increased sales by the competitor is to decrease sales, see equation (21)).

Economies of joint production and strategic substitutability both push firm $g$ to reduce sales in its domestic market.

When firm $g$ is confronted with diseconomies of scale and strategic complementarity, this combination causes firm $g$ to increase sales of its two products in domestic market $x$. In this case, however, the conditions $\Pi_{g}^{12}, \Pi_{g}^{45}>0$ mean in particular, by $(30)$, that

$$
\Pi_{g}^{12}=\left(p_{a x}^{12} x_{a}+p_{a x}^{2}+p_{b x}^{21} x_{b}^{g}+p_{b x}^{1}\right)-c_{g}^{12}>0 .
$$

The expression

$$
p_{a x}^{12} x_{a}+p_{a x}^{2}+p_{b x}^{21} x_{b}^{g}+p_{b x}^{1}
$$

which, roughly speaking, measures the degree of product complementarity, must be not only positive but also greater than $-c_{g}^{12}$. Thus, intuitively speaking, point (2) is valid only when the degree of product complementarity is high ${ }^{6}$.

Suppose now that goods $a$ and $b$ are independent on the demand $\operatorname{side}^{7}$, so that the relation between markets is established only through economies of joint production. In this case

$$
A_{1}=\left[\begin{array}{ccc}
\Pi_{g}^{11} & -c_{g}^{12} & 0 \\
-c_{g}^{12} & \Pi_{g}^{22} & \Pi_{g}^{23} \\
0 & \Pi_{m}^{32} & \Pi_{m}^{33}
\end{array}\right], A_{2}=\left[\begin{array}{ccc}
\Pi_{g}^{44} & -c_{g}^{12} & 0 \\
-c_{g}^{12} & \Pi_{g}^{55} & \Pi_{g}^{56} \\
0 & \Pi_{m}^{65} & \Pi_{m}^{66}
\end{array}\right] .
$$

\footnotetext{
${ }^{6}$ Note that in the linear framework $\Pi_{g}^{12}>0, \Pi_{g}^{45}>0$ if and only if goods are complements on the demand side.

${ }^{7}$ Note that if, in addition, the cost functions were linear, we would have a standard monopolist selling product $a$ in markets $x$ and $y$, on the one hand, and duopolists selling a homogeneous product $b$ in each other's markets on the other hand. The latter case in handled in Hens et al.(1991) and there is no point repeating their analysis here, except to recall that they show strategic substitutability to imply the firm specific effect.
} 
Proposition 5 If products are independent, there are no economies of scale and firm $g$ exhibits economies of joint production i.e., $c_{g}^{12}<0$, then after an appreciation of the currency of country $x$ we have the firm specific effect, if firm $g$ regards good $b$ as a strategic substitute in market $x$ i.e. $\Pi_{g}^{23}<0$ and firm $m$ regards good $b$ as a strategic substitute in both markets i.e. $\Pi_{m}^{32}, \Pi_{m}^{65}<0$. Moreover, the total sales of good $b$ decrease in country $y$.

Therefore prices of product a increase in both countries and the price of product $b$ increases in country $y$.

PROOF see Appendix.

Note that (if the products are independent), we have from (44)

$$
\Pi_{g}^{12}=\Pi_{g}^{45}=-c_{g}^{12} .
$$

which means that $\Pi_{g}^{12}>0$ if and only if firm $g$ has economies of joint production. Therefore we can say nothing in this case about the effects of diseconomies of joint production.

\section{The effects of economies of scale}

Suppose $c_{g}^{i j}=0$ for $i \neq j$ so that matrix $A_{3}$ is diagonal. Markets $x$ and $y$ are linked through economies of scale only. However, markets for goods $a$ and $b$ are separated. Firm $g$ can therefore be considered as a monopolist which is selling good $a$ in two markets and price discriminates across markets.

Proposition 6 If products are independent and there are no economies of joint production, then after a change of the exchange rate

(1) in case of economies of scale, i.e. $c_{g}^{11}, c_{g}^{22}, c_{m}^{\prime \prime}<0$, one can expect the firm specific effect if $b$ is regarded as a strategic substitute by both players in both countries, i.e. $\Pi_{g}^{23}, \Pi_{g}^{56}, \Pi_{m}^{32}, \Pi_{m}^{65}<0$. 
(2) in case of diseconomies of scale, i.e. $c_{g}^{11}, c_{g}^{22}, c_{m}^{\prime \prime}>0$, one can expect the country specific effect if $b$ is regarded as a strategic complement by both players, i.e. $\Pi_{g}^{23}, \Pi_{g}^{56}, \Pi_{m}^{32}, \Pi_{m}^{65}>0$. Therefore both prices go down in the country whose currency appreciates, and both prices go up in the other country.

\section{PROOF see Appendix.}

The intuition is straightforward. Firm $m$ faces lower sales of good $b$ by firm $g$ in market $y$. Hence, by strategic substitutability, firm $m$ has an incentive to increase sales in the home market. Moreover, firm $m$ sells more abroad. This decreases its marginal cost and, because of economies of scale, firm $m$ raises sales at home. As a consequence, strategic substitutability combined with economies of scale give firm $m$ an incentive to increase sales in its domestic market.

When firm $m$ is confronted with diseconomies of scale and strategic complementarity, this combination causes firm $m$ to reduce sales in its domestic market.

For firm $g$, both strategic substitutability and economies of scale push firm $g$ to reduce sales of good $b$ in its domestic market $x$. The combination of strategic complementarity and diseconomies of scale works in the opposite direction.

Proposition 6 is a straightforward generalization to a situation with two independent commodities of proposition 5 (which considers markets with one commodity) in Kirman and Phlips (1992). Notice that diseconomies of scale make sure that both prices move in the normal direction (down in the country that appreciates, up in the other country) when coupled with strategic complementarity for $b$. In the economies of scale case, all we are able to say about prices is that, since $g$ will sell less of $a$ in both countries, its price will go up in both countries too. This is a surprising result from the point of view of the standard literature of exchange rate pass-through. Yet, it is easily understood, since $g$ has the monopoly of commodity $a$ when $a$ is independent of $b$ from the consumers' point of view. 


\section{Conclusions}

In this paper effects of a change in the exchange rate on duopolistic behaviour are examined in the framework of a two-commodity model with joint production.

Our six propositions together imply that strategic substitutability or complementarity are the dominating forces whether the two commodities are substitutes, complements or independent from the consumers' point of view.

From the point of view of policy makers, a devaluation should improve domestic firm competitiveness in international markets and not lead to price increases. Policy makers would like the firm specific effect to occur, not the country specific effect, so that domestic firms sell more at home and abroad and domestic prices go down. Hence it is important to know which factors induce the firm specific effect and which factors lead to the country specific effect.

From the results obtained we can conclude that existence of strategic substitutability, economies of scale and/or economies of joint production lead to the firm specific effect.

If products are strategic complements and there are diseconomies of scale and/or diseconomies of joint production then we can expect a country specific effect.

There are still some open questions in this model. We can ask about the joint effect of factors which work in opposite directions. For example what is effect of economies of scale and strategic complementarity? There is also the very interesting question how a devaluation affects duopolists with other objective functions than profit maximization. 


\section{Appendix}

We will write matrix $A$ in (32) in slightly changed form as

$$
\left[\begin{array}{cccccc}
a_{11} & a_{12} & a_{13} & a_{14} & a_{15} & 0 \\
a_{21} & a_{22} & a_{23} & a_{24} & a_{25} & 0 \\
a_{31} & a_{32} & a_{33} & 0 & 0 & a_{36} \\
a_{41} & a_{42} & 0 & a_{44} & a_{45} & a_{46} \\
a_{51} & a_{52} & 0 & a_{54} & a_{55} & a_{56} \\
0 & 0 & a_{63} & a_{64} & a_{65} & a_{66}
\end{array}\right]\left[\begin{array}{c}
d x_{a} \\
d x_{b}^{g} \\
d x_{b}^{m} \\
d y_{a} \\
d y_{b}^{g} \\
d y_{b}^{m}
\end{array}\right]=\left[\begin{array}{c}
0 \\
0 \\
K \\
L \\
M \\
0
\end{array}\right] d e,
$$

where $a_{12}=a_{21}=\Pi_{g}^{12}, a_{14}=a_{41}=-c_{g}^{11}, a_{15}=a_{51}=a_{24}=a_{42}=-c_{g}^{12}$, $a_{25}=a_{52}=-c_{g}^{22}, a_{36}=a_{63}=-c_{m}^{\prime \prime}, a_{45}=a_{54}=\Pi_{g}^{45}$.

\subsection{Proofs of Propositions 2 and 3}

From equation (43) we have

(1) The sign of the $\frac{d x_{a}}{d e}$ is equal to the sign of the determinant

$$
\begin{array}{r}
=L\left|\begin{array}{cccc}
0 & \Pi_{g}^{12} & -c_{g}^{11} & -c_{g}^{12} \\
0 & \Pi_{g}^{22} & -c_{g}^{21} & -c_{g}^{22} \\
L & -c_{g}^{21} & \Pi_{g}^{44} & \Pi_{g}^{45} \\
M & -c_{g}^{22} & \Pi_{g}^{54} & \Pi_{g}^{55}
\end{array}\right| \\
=\left|\begin{array}{ccc}
\Pi_{g}^{12} & -c_{g}^{11} & -c_{g}^{12} \\
\Pi_{g}^{22} & -c_{g}^{21} & -c_{g}^{22} \\
-c_{g}^{22} & \Pi_{g}^{54} & \Pi_{g}^{55}
\end{array}\right|-M\left|\begin{array}{ccc}
\Pi_{g}^{12} & -c_{g}^{11} & -c_{g}^{12} \\
\Pi_{g}^{22} & -c_{g}^{21} & -c_{g}^{22} \\
-c_{g}^{21} & \Pi_{g}^{44} & \Pi_{g}^{45}
\end{array}\right|= \\
=L\left(c_{g}^{22}\left(\left(c_{g}^{12}\right)^{2}+\Pi_{g}^{12} \Pi_{g}^{45}\right)+c_{g}^{12}\left(-\Pi_{g}^{12} \Pi_{g}^{55}-\Pi_{g}^{45} \Pi_{g}^{22}\right)\right. \\
\left.+c_{g}^{11}\left|\begin{array}{cc}
\Pi_{g}^{22} & -c_{g}^{22} \\
-c_{g}^{22} & \Pi_{g}^{55}
\end{array}\right|\right)+M\left(c_{g}^{12}\left(\Pi_{g}^{12} \Pi_{g}^{45}+c_{g}^{11} c_{g}^{22}\right)\right.
\end{array}
$$




$$
\left.-\Pi_{g}^{12} \Pi_{g}^{44} c_{g}^{22}-c_{g}^{11} \Pi_{g}^{22} \Pi_{g}^{45}+c_{g}^{12}\left|\begin{array}{cc}
\Pi_{g}^{22} & -c_{g}^{21} \\
-c_{g}^{21} & \Pi_{g}^{44}
\end{array}\right|\right) .
$$

Therefore, if $\Pi_{g}^{12}=\Pi_{g}^{45}=0$ then

$\operatorname{sign}\left(\frac{d x_{a}^{g}}{d e}\right)=\operatorname{sign}\left\{L\left[c_{g}^{22}\left(c_{g}^{12}\right)^{2}+c_{g}^{11}(+)\right]+M\left[c_{g}^{12}\left(c_{g}^{11} c_{g}^{22}+(+)\right]\right\}\right.$.

If $\Pi_{g}^{12}>0$ and $\Pi_{g}^{45}>0$ and $\operatorname{sign} c_{g}^{11}=\operatorname{sign} c_{g}^{22}$ then

$$
\operatorname{sign}\left(\frac{d x_{a}^{g}}{d e}\right)=\operatorname{sign}\left\{(L+M)\left[c_{g}^{22}(+)+c_{g}^{12}(+)+c_{g}^{11}(+)\right] .\right.
$$

(2) The sign of the $\frac{d x_{b}^{g}}{d e}$ is equal to the sign of the determinant

$$
\begin{gathered}
\quad\left|\begin{array}{cccc}
\Pi_{g}^{11} & 0 & -c_{g}^{11} & -c_{g}^{12} \\
\Pi_{g}^{21} & 0 & -c_{g}^{21} & -c_{g}^{22} \\
-c_{g}^{11} & L & \Pi_{g}^{44} & \Pi_{g}^{45} \\
-c_{g}^{12} & M & \Pi_{g}^{54} & \Pi_{g}^{55}
\end{array}\right|= \\
=L\left(c_{g}^{12}\left(\Pi_{g}^{45} \Pi_{g}^{12}+c_{g}^{11} c_{g}^{22}\right)-\Pi_{g}^{12} \Pi_{g}^{55} c_{g}^{11}-\Pi_{g}^{45} \Pi_{g}^{11} c_{g}^{22}\right. \\
\left.+c_{g}^{12}\left|\begin{array}{cc}
\Pi_{g}^{11} & -c_{g}^{12} \\
-c_{g}^{12} & \Pi_{g}^{55}
\end{array}\right|\right)+M\left(c_{g}^{11}\left(\left(c_{g}^{12}\right)^{2}+\Pi_{g}^{45} \Pi_{g}^{12}\right)\right. \\
\left.+c_{g}^{12}\left(-\Pi_{g}^{12} \Pi_{g}^{44}-\Pi_{g}^{45} \Pi_{g}^{11}\right)+c_{g}^{22}\left|\begin{array}{cc}
\Pi_{g}^{11} & -c_{g}^{11} \\
-c_{g}^{11} & \Pi_{g}^{44}
\end{array}\right|\right) .
\end{gathered}
$$

Therefore, if $\Pi_{g}^{12}=\Pi_{g}^{45}=0$ then

$$
\begin{aligned}
\operatorname{sign}\left(\frac{d x_{b}^{g}}{d e}\right)= & \operatorname{sign}\left\{L \left[c_{g}^{12}\left(c_{g}^{11} c_{g}^{22}+(+)\right]\right.\right. \\
& \left.+M\left[c_{g}^{11}\left(c_{g}^{12}\right)^{2}+c_{g}^{22}(+)\right]\right\} .
\end{aligned}
$$

If $\Pi_{g}^{12}>0$ and $\Pi_{g}^{45}>0$ and $\operatorname{sign} c_{g}^{11}=\operatorname{sign} c_{g}^{22}$ then $\operatorname{sign}\left(\frac{d x_{b}^{g}}{d e}\right)=\operatorname{sign}\left\{L\left[c_{g}^{12}(+)+c_{g}^{11}(+)+c_{g}^{22}(+)\right]+M\left[c_{g}^{11}(+)+c_{g}^{12}(+)+c_{g}^{22}(+)\right]\right\}$. 
(3) The sign of the $\frac{d y_{a}}{d e}$ is equal to the sign of the determinant

$$
\begin{array}{r}
\left|\begin{array}{cccc}
\Pi_{g}^{11} & \Pi_{g}^{12} & 0 & -c_{g}^{12} \\
\Pi_{g}^{21} & \Pi_{g}^{22} & 0 & -c_{g}^{22} \\
-c_{g}^{11} & -c_{g}^{21} & L & \Pi_{g}^{45} \\
-c_{g}^{12} & -c_{g}^{22} & M & \Pi_{g}^{55}
\end{array}\right|=L\left|\begin{array}{ccc}
\Pi_{g}^{11} & \Pi_{g}^{12} & -c_{g}^{12} \\
\Pi_{g}^{21} & \Pi_{g}^{22} & -c_{g}^{22} \\
-c_{g}^{12} & -c_{g}^{22} & \Pi_{g}^{55}
\end{array}\right|+ \\
+M\left(\Pi_{g}^{12}\left(-c_{g}^{11} c_{g}^{22}-\left(c_{g}^{12}\right)^{2}\right)+c_{g}^{12}\left(c_{g}^{11} \Pi_{g}^{22}+c_{g}^{22} \Pi_{g}^{11}\right)\right. \\
\left.-\Pi_{g}^{45}\left|\begin{array}{ll}
\Pi_{g}^{11} & \Pi_{g}^{12} \\
\Pi_{g}^{21} & \Pi_{g}^{22}
\end{array}\right|\right)
\end{array}
$$

Therefore, if $\Pi_{g}^{12}=\Pi_{g}^{45}=0$ then

$$
\operatorname{sign}\left(\frac{d y_{a}^{g}}{d e}\right)=\operatorname{sign}\left\{L(-)+M\left[c_{g}^{12}\left(c_{g}^{11}(-)+c_{g}^{22}(-)\right)\right]\right\} .
$$

If $\Pi_{g}^{12}>0$ and $\Pi_{g}^{45}>0$ and $\operatorname{sign} c_{g}^{11}=\operatorname{sign} c_{g}^{22}$ then $\operatorname{sign}\left(\frac{d y_{a}^{g}}{d e}\right)=\operatorname{sign}\left\{L(-)+M\left[-c_{g}^{11} c_{g}^{22}+c_{g}^{12}\left(c_{g}^{11}(-)+c_{g}^{22}(-)\right)-(+)\right]\right\}$.

(4) The sign of the $\frac{d y_{b}^{g}}{d e}$ is equal to the sign of the determinant

$$
\begin{gathered}
\left|\begin{array}{cccc}
\Pi_{g}^{11} & \Pi_{g}^{12} & -c_{g}^{11} & 0 \\
\Pi_{g}^{21} & \Pi_{g}^{22} & -c_{g}^{21} & 0 \\
-c_{g}^{11} & -c_{g}^{21} & \Pi_{g}^{44} & L \\
-c_{g}^{12} & -c_{g}^{22} & \Pi_{g}^{54} & M
\end{array}\right|=M\left|\begin{array}{ccc}
\Pi_{g}^{11} & \Pi_{g}^{12} & -c_{g}^{11} \\
\Pi_{g}^{21} & \Pi_{g}^{22} & -c_{g}^{21} \\
-c_{g}^{11} & -c_{g}^{21} & \Pi_{g}^{44}
\end{array}\right|+ \\
L\left(\Pi_{g}^{12}\left(-\left(c_{g}^{12}\right)^{2}-c_{g}^{11} c_{g}^{22}\right)+c_{g}^{12}\left(c_{g}^{11} \Pi_{g}^{22}+c_{g}^{22} \Pi_{g}^{11}\right)-\Pi_{g}^{45}\left|\begin{array}{cc}
\Pi_{g}^{11} & \Pi_{g}^{12} \\
\Pi_{g}^{21} & \Pi_{g}^{22}
\end{array}\right|\right) .
\end{gathered}
$$

Therefore, if $\Pi_{g}^{12}=\Pi_{g}^{45}=0$ then

$$
\operatorname{sign}\left(\frac{d y_{b}^{g}}{d e}\right)=\operatorname{sign}\left\{M(-)+L\left[c_{g}^{12}\left(c_{g}^{11}(-)+c_{g}^{22}(-)\right)\right]\right\} .
$$


If $\Pi_{g}^{12}>0$ and $\Pi_{g}^{45}>0$ and $\operatorname{sign} c_{g}^{11}=\operatorname{sign} c_{g}^{22}$ then

$$
\operatorname{sign}\left(\frac{d y_{b}^{g}}{d e}\right)=\operatorname{sign}\left\{M(-)+L\left[-c_{g}^{11} c_{g}^{22}+c_{g}^{12}\left(c_{g}^{11}(-)+c_{g}^{22}(-)\right)-(+)\right]\right\} .
$$

Proposition 2 follows immediately from equations (47), (49), (51) and (53).

From equations (48), (50), (52) and (54) one gets immediately proposition 3 .

\subsection{Proof of Propositions 4 and 5}

If goods $a$ and $b$ are differentiated, $c_{g}^{12} \neq 0$ and $c_{g}^{11}=c_{g}^{22}=c_{m}^{\prime \prime}=0$, matrix $A$ is equal to

$$
\left[\begin{array}{cccccc}
a_{11} & a_{12} & a_{13} & 0 & a_{15} & 0 \\
a_{12} & a_{22} & a_{23} & a_{15} & 0 & 0 \\
a_{31} & a_{32} & a_{33} & 0 & 0 & 0 \\
0 & a_{15} & 0 & a_{44} & a_{45} & a_{46} \\
a_{15} & 0 & 0 & a_{45} & a_{55} & a_{56} \\
0 & 0 & 0 & a_{64} & a_{65} & a_{66}
\end{array}\right] .
$$

(1) The sign of $d x_{a}^{g} / d e$ is equal to

$$
\begin{gathered}
\left|\begin{array}{cccccc}
0 & a_{12} & a_{13} & 0 & a_{15} & 0 \\
0 & a_{22} & a_{23} & a_{15} & 0 & 0 \\
K & a_{32} & a_{33} & 0 & 0 & 0 \\
L & a_{15} & 0 & a_{44} & a_{45} & a_{46} \\
M & 0 & 0 & a_{45} & a_{55} & a_{56} \\
0 & 0 & 0 & a_{64} & a_{65} & a_{66}
\end{array}\right|=K\left|\begin{array}{ccccc}
a_{12} & a_{13} & 0 & a_{15} & 0 \\
a_{22} & a_{23} & a_{15} & 0 & 0 \\
a_{15} & 0 & a_{44} & a_{45} & a_{46} \\
0 & 0 & a_{45} & a_{55} & a_{56} \\
0 & 0 & a_{64} & a_{65} & a_{66}
\end{array}\right| \\
-L\left|\begin{array}{ccccc}
a_{12} & a_{13} & 0 & a_{15} & 0 \\
a_{22} & a_{23} & a_{15} & 0 & 0 \\
a_{32} & a_{33} & 0 & 0 & 0 \\
0 & 0 & a_{45} & a_{55} & a_{56} \\
0 & 0 & a_{64} & a_{65} & a_{66}
\end{array}\right|+M\left|\begin{array}{ccccc}
a_{12} & a_{13} & 0 & a_{15} & 0 \\
a_{22} & a_{23} & a_{15} & 0 & 0 \\
a_{32} & a_{33} & 0 & 0 & 0 \\
a_{15} & 0 & a_{44} & a_{45} & a_{46} \\
0 & 0 & a_{64} & a_{65} & a_{66}
\end{array}\right|
\end{gathered}
$$




$$
\begin{aligned}
& =K\left(-a_{13}\left|\begin{array}{cccc}
a_{22} & a_{15} & 0 & 0 \\
a_{15} & a_{44} & a_{45} & a_{46} \\
0 & a_{45} & a_{55} & a_{56} \\
0 & a_{64} & a_{65} & a_{66}
\end{array}\right|+a_{23}\left|\begin{array}{cccc}
a_{12} & 0 & a_{15} & 0 \\
a_{15} & a_{44} & a_{45} & a_{46} \\
0 & a_{45} & a_{55} & a_{56} \\
0 & a_{64} & a_{65} & a_{66}
\end{array}\right|\right) \\
& -L\left(a_{32}\left|\begin{array}{cccc}
a_{13} & 0 & a_{15} & 0 \\
a_{23} & a_{15} & 0 & 0 \\
0 & a_{45} & a_{55} & a_{56} \\
0 & a_{64} & a_{65} & a_{66}
\end{array}\right|-a_{33}\left|\begin{array}{cccc}
a_{12} & 0 & a_{15} & 0 \\
a_{22} & a_{15} & 0 & 0 \\
0 & a_{45} & a_{55} & a_{56} \\
0 & a_{64} & a_{65} & a_{66}
\end{array}\right|\right) \\
& +M\left(-a_{15}\left|\begin{array}{cccc}
a_{22} & a_{23} & a_{15} & 0 \\
a_{32} & a_{33} & 0 & 0 \\
a_{15} & 0 & a_{44} & a_{46} \\
0 & 0 & a_{64} & a_{66}
\end{array}\right|+a_{45}\left|\begin{array}{cccc}
a_{12} & a_{13} & 0 & 0 \\
a_{22} & a_{23} & a_{15} & 0 \\
a_{32} & a_{33} & 0 & 0 \\
0 & 0 & a_{64} & a_{66}
\end{array}\right|\right. \\
& \left.-a_{65}\left|\begin{array}{cccc}
a_{12} & a_{13} & 0 & 0 \\
a_{22} & a_{23} & a_{15} & 0 \\
a_{32} & a_{33} & 0 & 0 \\
0 & 0 & a_{45} & a_{46}
\end{array}\right|\right)= \\
& K\left[-a_{13}(+)+a_{23}\left(a_{12}\left|\begin{array}{ccc}
a_{44} & a_{45} & a_{46} \\
a_{45} & a_{55} & a_{56} \\
a_{64} & a_{65} & a_{66}
\end{array}\right|+a_{15}\left|\begin{array}{ccc}
a_{15} & a_{44} & a_{46} \\
0 & a_{45} & a_{56} \\
0 & a_{64} & a_{66}
\end{array}\right|\right)\right] \\
& -L\left[a_{32}\left(a_{13}\left|\begin{array}{ccc}
a_{15} & 0 & 0 \\
a_{45} & a_{55} & a_{56} \\
a_{64} & a_{65} & a_{66}
\end{array}\right|-a_{23}\left|\begin{array}{ccc}
0 & a_{15} & 0 \\
a_{45} & a_{55} & a_{56} \\
a_{64} & a_{65} & a_{66}
\end{array}\right|\right)\right. \\
& \left.-a_{33}\left(a_{12}\left|\begin{array}{ccc}
a_{15} & 0 & 0 \\
a_{45} & a_{55} & a_{56} \\
a_{64} & a_{65} & a_{66}
\end{array}\right|-a_{22}\left|\begin{array}{ccc}
0 & a_{15} & 0 \\
a_{45} & a_{55} & a_{56} \\
a_{64} & a_{65} & a_{66}
\end{array}\right|\right)\right] \\
& +M\left(-a_{15}(+)+a_{45} a_{66}\left|\begin{array}{ccc}
a_{12} & a_{13} & 0 \\
a_{22} & a_{23} & a_{15} \\
a_{32} & a_{33} & 0
\end{array}\right|-a_{65} a_{56}\left|\begin{array}{ccc}
a_{12} & a_{13} & 0 \\
a_{22} & a_{23} & a_{15} \\
a_{32} & a_{33} & 0
\end{array}\right|\right) \\
& =K\left[-a_{13}(+)+a_{23} a_{12}(-)+a_{23}\left(a_{15}\right)^{2}\left(a_{45} a_{66}-a_{56} a_{64}\right)\right] \\
& -L\left\{a_{32} a_{15}\left[a_{13}(+)+a_{23}\left(a_{45} a_{66}-a_{56} a_{64}\right)\right]\right.
\end{aligned}
$$




$$
\begin{array}{r}
\left.-a_{33} a_{15}\left[a_{12}(+)+a_{22}\left(a_{45} a_{66}-a_{56} a_{64}\right)\right]\right\} \\
+M\left(-a_{15}\right)\left[(+)+\left(a_{45} a_{66}-a_{46} a_{65}\right)\left(a_{12} a_{33}-a_{13} a_{32}\right)\right] \\
=K\left[-a_{13}(+)+a_{23} a_{12}(-)+a_{23}\left(a_{15}\right)^{2}\left(a_{45} a_{66}-a_{56} a_{64}\right)\right] \\
+L\left(-a_{15}\right)\left[a_{32} a_{13}(+)-a_{33} a_{12}(+)+\left(a_{32} a_{23}-a_{22} a_{33}\right)\left(a_{45} a_{66}-a_{56} a_{64}\right)\right] \\
+M\left(-a_{15}\right)\left[(+)+\left(a_{45} a_{66}-a_{46} a_{65}\right)\left(a_{12} a_{33}-a_{13} a_{32}\right)\right] \\
=(-K)\left[a_{13}(+)-a_{23} a_{12}(-)-a_{23}\left(a_{15}\right)^{2}\left(a_{45} a_{66}-a_{56} a_{64}\right)\right] \\
+L\left(-a_{15}\right)\left[a_{32} a_{13}(+)-a_{33} a_{12}(+)+(-)\left(a_{45} a_{66}-a_{56} a_{64}\right)\right] \\
\quad+M\left(-a_{15}\right)\left[(+)+\left(a_{45} a_{66}-a_{46} a_{65}\right)\left(a_{12} a_{33}-a_{13} a_{32}\right)\right]
\end{array}
$$

Therefore, if $a_{12}>0, a_{45}>0, a_{13} a_{32}>0, a_{46} a_{65}>0$ and $a_{56} a_{64}>0$, then $a_{45} a_{66}-a_{56} a_{64}<0, a_{45} a_{66}-a_{46} a_{65}<0$ and $a_{12} a_{33}-a_{13} a_{32}<0$.

In this case the sign of $d x_{a}^{g} / d e$ is equal to

$$
-K\left[a_{13}(+)+a_{23}(+)\right]+L\left(-a_{15}\right)(+)+M\left(-a_{15}\right)(+) .
$$

If $a_{15}=a_{12}=a_{45}$ and $a_{13}=a_{31}=a_{46}=a_{64}=0$, i.e. goods are independent, then the sign of $d x_{a}^{g} / d e$ is equal to

$$
K a_{15} a_{23}(-)+L a_{15}^{2}(-)+M a_{15}(-) .
$$

(2) The sign of $d x_{b}^{g} / d e$ is equal to

$$
\begin{aligned}
& \left|\begin{array}{cccccc}
a_{11} & 0 & a_{13} & 0 & a_{15} & 0 \\
a_{12} & 0 & a_{23} & a_{15} & 0 & 0 \\
a_{31} & K & a_{33} & 0 & 0 & 0 \\
0 & L & 0 & a_{44} & a_{45} & a_{46} \\
a_{15} & M & 0 & a_{45} & a_{55} & a_{56} \\
0 & 0 & 0 & a_{64} & a_{65} & a_{66}
\end{array}\right|=-K\left|\begin{array}{ccccc}
a_{11} & a_{13} & 0 & a_{15} & 0 \\
a_{12} & a_{23} & a_{15} & 0 & 0 \\
0 & 0 & a_{44} & a_{45} & a_{46} \\
a_{15} & 0 & a_{45} & a_{55} & a_{56} \\
0 & 0 & a_{64} & a_{65} & a_{66}
\end{array}\right| \\
& +L\left|\begin{array}{ccccc}
a_{11} & a_{13} & 0 & a_{15} & 0 \\
a_{12} & a_{23} & a_{15} & 0 & 0 \\
a_{31} & a_{33} & 0 & 0 & 0 \\
a_{15} & 0 & a_{45} & a_{55} & a_{56} \\
0 & 0 & a_{64} & a_{65} & a_{66}
\end{array}\right|-M\left|\begin{array}{ccccc}
a_{11} & a_{13} & 0 & a_{15} & 0 \\
a_{12} & a_{23} & a_{15} & 0 & 0 \\
a_{31} & a_{33} & 0 & 0 & 0 \\
0 & 0 & a_{44} & a_{45} & a_{46} \\
0 & 0 & a_{64} & a_{65} & a_{66}
\end{array}\right| \\
& =-K\left(-a_{13}\left|\begin{array}{cccc}
a_{12} & a_{15} & 0 & 0 \\
0 & a_{44} & a_{45} & a_{46} \\
a_{15} & a_{45} & a_{55} & a_{56} \\
0 & a_{64} & a_{65} & a_{66}
\end{array}\right|+a_{23}\left|\begin{array}{cccc}
a_{11} & 0 & a_{15} & 0 \\
0 & a_{44} & a_{45} & a_{46} \\
a_{15} & a_{45} & a_{55} & a_{56} \\
0 & a_{64} & a_{65} & a_{66}
\end{array}\right|\right)
\end{aligned}
$$




$$
\begin{aligned}
& +L\left(-a_{15}\left|\begin{array}{cccc}
a_{11} & a_{13} & a_{15} & 0 \\
a_{31} & a_{33} & 0 & 0 \\
a_{15} & 0 & a_{55} & a_{56} \\
0 & 0 & a_{65} & a_{66}
\end{array}\right|-a_{45}\left|\begin{array}{cccc}
a_{11} & a_{13} & a_{15} & 0 \\
a_{12} & a_{23} & 0 & 0 \\
a_{31} & a_{33} & 0 & 0 \\
0 & 0 & a_{65} & a_{66}
\end{array}\right|\right. \\
& \left.+a_{64}\left|\begin{array}{cccc}
a_{11} & a_{13} & a_{15} & 0 \\
a_{12} & a_{23} & 0 & 0 \\
a_{31} & a_{33} & 0 & 0 \\
a_{15} & 0 & a_{55} & a_{56}
\end{array}\right|\right) \\
& -M\left(a_{31}\left|\begin{array}{cccc}
a_{13} & 0 & a_{15} & 0 \\
a_{23} & a_{15} & 0 & 0 \\
0 & a_{44} & a_{45} & a_{46} \\
0 & a_{64} & a_{65} & a_{66}
\end{array}\right|-a_{33}\left|\begin{array}{cccc}
a_{11} & 0 & a_{15} & 0 \\
a_{12} & a_{15} & 0 & 0 \\
0 & a_{44} & a_{45} & a_{46} \\
0 & a_{64} & a_{65} & a_{66}
\end{array}\right|\right) \\
& =-K\left[-a_{13}\left(a_{12}\left|\begin{array}{lll}
a_{44} & a_{45} & a_{46} \\
a_{45} & a_{55} & a_{56} \\
a_{64} & a_{65} & a_{66}
\end{array}\right|+a_{15}\left|\begin{array}{ccc}
a_{15} & 0 & 0 \\
a_{44} & a_{45} & a_{46} \\
a_{64} & a_{65} & a_{66}
\end{array}\right|\right)+a_{23}(+)\right] \\
& +L\left(-a_{15}(+)-a_{45} a_{66} a_{15}\left|\begin{array}{cc}
a_{12} & a_{23} \\
a_{31} & a_{33}
\end{array}\right|+a_{64} a_{56} a_{15}\left|\begin{array}{ll}
a_{12} & a_{23} \\
a_{31} & a_{33}
\end{array}\right|\right) \\
& -M\left[a_{31}\left(a_{13} a_{15}\left|\begin{array}{ll}
a_{45} & a_{46} \\
a_{65} & a_{66}
\end{array}\right|+a_{15} a_{23}\left|\begin{array}{cc}
a_{44} & a_{46} \\
a_{64} & a_{66}
\end{array}\right|\right)\right. \\
& \left.-a_{33}\left(a_{11} a_{15}\left|\begin{array}{ll}
a_{45} & a_{46} \\
a_{65} & a_{66}
\end{array}\right|+a_{15} a_{12}\left|\begin{array}{cc}
a_{44} & a_{46} \\
a_{64} & a_{66}
\end{array}\right|\right)\right] \\
& =-K\left\{-a_{13}\left[a_{12}(-)+\left(a_{15}\right)^{2}\left(a_{45} a_{66}-a_{46} a_{65}\right)\right]+a_{23}(+)\right\} \\
& +L\left(-a_{15}\right)\left[(+)+\left(a_{45} a_{66}-a_{64} a_{56}\right)\left(a_{12} a_{33}-a_{23} a_{31}\right)\right] \\
& +M\left(-a_{15}\right)\left(\left(a_{31} a_{13}-a_{33} a_{11}\right)\left|\begin{array}{ll}
a_{45} & a_{46} \\
a_{65} & a_{66}
\end{array}\right|\right. \\
& \left.+\left(a_{31} a_{23}-a_{33} a_{12}\right)\left|\begin{array}{ll}
a_{44} & a_{46} \\
a_{64} & a_{66}
\end{array}\right|\right) \\
& =-K\left\{-a_{13}\left[a_{12}(-)+\left(a_{15}\right)^{2}\left(a_{45} a_{66}-a_{46} a_{65}\right)\right]+a_{23}(+)\right\}
\end{aligned}
$$




$$
\begin{array}{r}
+L\left(-a_{15}\right)\left[(+)+\left(a_{45} a_{66}-a_{64} a_{56}\right)\left(a_{12} a_{33}-a_{23} a_{31}\right)\right] \\
+M\left(-a_{15}\right)\left[\left(a_{45} a_{66}-a_{46} a_{65}\right)(-)+\left(a_{31} a_{23}-a_{33} a_{12}\right)(+)\right] .
\end{array}
$$

Therefore, if $a_{12}>0, a_{45}>0, a_{46} a_{65}>0$ and $a_{64} a_{56}>0$ and $a_{31} a_{23}>0$, then

$a_{45} a_{66}-a_{46} a_{65}<0$ and $a_{12} a_{33}-a_{23} a_{31}<0$.

In this case the sign of $d x_{b}^{g} / d e$ is equal to

$$
-K\left\{-a_{13}\left[(-)+a_{15}^{2}(-)\right]+a_{23}(+)\right\}+L\left(-a_{15}\right)(+)+M\left(-a_{15}\right)(+) \text {. }
$$

If $a_{15}=a_{12}=a_{45}$ and $a_{13}=a_{31}=a_{46}=a_{64}=0$, i.e. goods are independent, then the sign of $d x_{b}^{g} / d e$ is equal to

$$
-K a_{23}(+)+L\left(-a_{15}\right)(+)+M a_{15}^{2}(-) \text {. }
$$

(3) The sign of $d x_{b}^{m} / d e$ is equal to

$$
\begin{aligned}
& \left|\begin{array}{cccccc}
a_{11} & a_{12} & 0 & 0 & a_{15} & 0 \\
a_{12} & a_{22} & 0 & a_{15} & 0 & 0 \\
a_{31} & a_{32} & K & 0 & 0 & 0 \\
0 & a_{15} & L & a_{44} & a_{45} & a_{46} \\
a_{15} & 0 & M & a_{45} & a_{55} & a_{56} \\
0 & 0 & 0 & a_{64} & a_{65} & a_{66}
\end{array}\right|=K\left|\begin{array}{ccccc}
a_{11} & a_{12} & 0 & a_{15} & 0 \\
a_{12} & a_{22} & a_{15} & 0 & 0 \\
0 & a_{15} & a_{44} & a_{45} & a_{46} \\
a_{15} & 0 & a_{45} & a_{55} & a_{56} \\
0 & 0 & a_{64} & a_{65} & a_{66}
\end{array}\right| \\
& -L\left|\begin{array}{ccccc}
a_{11} & a_{12} & 0 & a_{15} & 0 \\
a_{12} & a_{22} & a_{15} & 0 & 0 \\
a_{31} & a_{32} & 0 & 0 & 0 \\
a_{15} & 0 & a_{45} & a_{55} & a_{56} \\
0 & 0 & a_{64} & a_{65} & a_{66}
\end{array}\right|+M\left|\begin{array}{ccccc}
a_{11} & a_{12} & 0 & a_{15} & 0 \\
a_{12} & a_{22} & a_{15} & 0 & 0 \\
a_{31} & a_{32} & 0 & 0 & 0 \\
0 & a_{15} & a_{44} & a_{45} & a_{46} \\
0 & 0 & a_{64} & a_{65} & a_{66}
\end{array}\right| \\
& =K(-)-L\left(a_{31}\left|\begin{array}{cccc}
a_{12} & 0 & a_{15} & 0 \\
a_{22} & a_{15} & 0 & 0 \\
0 & a_{45} & a_{55} & a_{56} \\
0 & a_{64} & a_{65} & a_{66}
\end{array}\right|-a_{32}\left|\begin{array}{cccc}
a_{11} & 0 & a_{15} & 0 \\
a_{12} & a_{15} & 0 & 0 \\
a_{15} & a_{45} & a_{55} & a_{56} \\
0 & a_{64} & a_{65} & a_{66}
\end{array}\right|\right) \\
& +M\left[a_{31}\left|\begin{array}{cccc}
a_{12} & 0 & a_{15} & 0 \\
a_{22} & a_{15} & 0 & 0 \\
a_{15} & a_{44} & a_{45} & a_{46}^{-} \\
0 & a_{64} & a_{65} & a_{66}
\end{array}\right|-a_{32}\left|\begin{array}{cccc}
a_{11} & 0 & a_{15} & 0 \\
a_{12} & a_{15} & 0 & 0 \\
0 & a_{44} & a_{45} & a_{46} \\
0 & a_{64} & a_{65} & a_{66}
\end{array}\right|\right]
\end{aligned}
$$




$$
\begin{aligned}
& =K(-)-L\left[a_{31}\left(a_{12} a_{15}\left|\begin{array}{ll}
a_{55} & a_{56} \\
a_{65} & a_{66}
\end{array}\right|+a_{15} a_{22}\left|\begin{array}{ll}
a_{45} & a_{56} \\
a_{64} & a_{66}
\end{array}\right|\right)\right. \\
& \left.-a_{32}\left(a_{15}\left|\begin{array}{ccc}
a_{11} & a_{15} & 0 \\
a_{15} & a_{55} & a_{56} \\
0 & a_{65} & a_{66}
\end{array}\right|-a_{12}\left|\begin{array}{ccc}
0 & a_{15} & 0 \\
a_{45} & a_{55} & a_{56} \\
a_{64} & a_{65} & a_{66}
\end{array}\right|\right)\right] \\
& +M\left[a_{31}\left(a_{12}\left|\begin{array}{ccc}
a_{15} & 0 & 0 \\
a_{44} & a_{45} & a_{46} \\
a_{64} & a_{65} & a_{66}
\end{array}\right|+a_{15}\left|\begin{array}{ccc}
a_{22} & a_{15} & 0 \\
a_{15} & a_{44} & a_{46} \\
0 & a_{64} & a_{66}
\end{array}\right|\right)\right. \\
& \left.-a_{32}\left(a_{11}\left|\begin{array}{ccc}
a_{15} & 0 & 0 \\
a_{44} & a_{45} & a_{46} \\
a_{64} & a_{65} & a_{66}
\end{array}\right|+a_{15}\left|\begin{array}{ccc}
a_{12} & a_{15} & 0 \\
0 & a_{44} & a_{46} \\
0 & a_{64} & a_{66}
\end{array}\right|\right)\right] \\
& =K(-)+L\left(-a_{15}\right)\left\{a_{31}\left[a_{12}(+)+a_{22}\left(a_{45} a_{66}-a_{56} a_{64}\right)\right]\right. \\
& \left.-a_{32}\left[(-)+a_{12}\left(a_{45} a_{66}-a_{56} a_{64}\right)\right]\right\} \\
& =M a_{15}\left\{a_{31}\left[a_{12}\left(a_{45} a_{66}-a_{46} a_{65}\right)+(-)\right]\right. \\
& \left.-a_{32}\left[a_{11}\left(a_{45} a_{66}-a_{46} a_{65}\right)+a_{12}(+)\right]\right\} \\
& =(-) K+L\left(-a_{15}\right)\left\{a_{31}\left[a_{12}(+)+a_{22}\left(a_{45} a_{66}-a_{56} a_{64}\right)\right]\right. \\
& \left.+a_{32}\left[(+)-a_{12}\left(a_{45} a_{66}-a_{56} a_{64}\right)\right]\right\} \\
& =M a_{15}\left\{a_{31}\left[a_{12}\left(a_{45} a_{66}-a_{46} a_{65}\right)+(-)\right]\right. \\
& \left.+a_{32}\left[-a_{11}\left(a_{45} a_{66}-a_{46} a_{65}\right)-a_{12}(+)\right]\right\} \text {. }
\end{aligned}
$$

Therefore, if $a_{12}>0, a_{45}>0, a_{56} a_{64}>0$ and $a_{46} a_{65}>0$, then $a_{45} a_{66}-a_{56} a_{64}<0$ and $a_{45} a_{66}-a_{46} a_{65}>0$.

In this case the sign of $d x_{b}^{m} / d e$ is equal to

$$
K(-)+L a_{15}\left[a_{31}(-)+a_{32}(-)\right]+M a_{15}\left[a_{31}(-)+a_{32}(-)\right]
$$

If $a_{15}=a_{12}=a_{45}$ and $a_{13}=a_{31}=a_{46}=a_{64}=0$, i.e. goods are independent, then the sign of $d x_{b}^{m} / d e$ is equal to

$$
(-) K+M a_{15}^{2} a_{32}(-)+L a_{15} a_{32}(-)
$$


(4) The sign of $d y_{a}^{g} / d e$ is equal to

$$
\begin{aligned}
& \left|\begin{array}{cccccc}
a_{11} & a_{12} & a_{13} & 0 & a_{15} & 0 \\
a_{12} & a_{22} & a_{23} & 0 & 0 & 0 \\
a_{31} & a_{32} & a_{33} & K & 0 & 0 \\
0 & a_{15} & 0 & L & a_{45} & a_{46} \\
a_{15} & 0 & 0 & M & a_{55} & a_{56} \\
0 & 0 & 0 & 0 & a_{65} & a_{66}
\end{array}\right|=-K\left|\begin{array}{ccccc}
a_{11} & a_{12} & a_{13} & a_{15} & 0 \\
a_{12} & a_{22} & a_{23} & 0 & 0 \\
0 & a_{15} & 0 & a_{45} & a_{46} \\
a_{15} & 0 & 0 & a_{55} & a_{56} \\
0 & 0 & 0 & a_{65} & a_{66}
\end{array}\right| \\
& +L\left|\begin{array}{ccccc}
a_{11} & a_{12} & a_{13} & a_{15} & 0 \\
a_{12} & a_{22} & a_{23} & 0 & 0 \\
a_{31} & a_{32} & a_{33} & 0 & 0 \\
a_{15} & 0 & 0 & a_{55} & a_{56} \\
0 & 0 & 0 & a_{65} & a_{66}
\end{array}\right|-M\left|\begin{array}{ccccc}
a_{11} & a_{12} & a_{13} & a_{15} & 0 \\
a_{12} & a_{22} & a_{23} & 0 & 0 \\
a_{31} & a_{32} & a_{33} & 0 & 0 \\
0 & a_{15} & 0 & a_{45} & a_{46} \\
0 & 0 & 0 & a_{65} & a_{66}
\end{array}\right| \\
& =L(-)-K\left(a_{13}\left|\begin{array}{cccc}
a_{12} & a_{22} & 0 & 0 \\
0 & a_{15} & a_{45} & a_{46} \\
a_{15} & 0 & a_{55} & a_{56} \\
0 & 0 & a_{65} & a_{66}
\end{array}\right|-a_{23}\left|\begin{array}{cccc}
a_{11} & a_{12} & a_{15} & 0 \\
0 & a_{15} & a_{45} & a_{46} \\
a_{15} & 0 & a_{55} & a_{56} \\
0 & 0 & a_{65} & a_{66}
\end{array}\right|\right) \\
& +M\left(-a_{46} a_{65}\left|\begin{array}{ccc}
a_{11} & a_{12} & a_{13} \\
a_{12} & a_{22} & a_{23} \\
a_{31} & a_{32} & a_{33}
\end{array}\right|+a_{66}\left|\begin{array}{cccc}
a_{11} & a_{12} & a_{13} & a_{15} \\
a_{12} & a_{22} & a_{23} & 0 \\
a_{31} & a_{32} & a_{33} & 0 \\
0 & a_{15} & 0 & a_{45}
\end{array}\right|\right) \\
& =L(-)-K\left[a_{13}\left(a_{12} a_{15}\left|\begin{array}{cc}
a_{55} & a_{56} \\
a_{65} & a_{66}
\end{array}\right|+a_{22} a_{15}\left|\begin{array}{cc}
a_{45} & a_{46} \\
a_{65} & a_{66}
\end{array}\right|\right)\right. \\
& \left.-a_{23}\left(a_{12} a_{15}\left|\begin{array}{ll}
a_{45} & a_{46} \\
a_{65} & a_{66}
\end{array}\right|+a_{15}\left|\begin{array}{ccc}
a_{11} & a_{15} & 0 \\
a_{15} & a_{55} & a_{56} \\
0 & a_{65} & a_{66}
\end{array}\right|\right)\right] \\
& +M\left[-a_{46} a_{65}(-)+a_{66}\left(a_{45}\left|\begin{array}{lll}
a_{11} & a_{12} & a_{13} \\
a_{12} & a_{22} & a_{23} \\
a_{31} & a_{32} & a_{33}
\end{array}\right|+\left(a_{15}\right)^{2}\left|\begin{array}{cc}
a_{12} & a_{23} \\
a_{31} & a_{33}
\end{array}\right|\right)\right] \\
& =L(-)-K a_{15}\left[a_{13} a_{12}(+)+\left(a_{22} a_{13}-a_{23} a_{12}\right)\left(a_{45} a_{66}-a_{45} a_{65}\right)-a_{23}(-)\right] \\
& -M\left[-a_{46} a_{65}(-)+a_{66} a_{45}(-)+a_{66}\left(a_{15}\right)^{2}\left(a_{12} a_{33}-a_{23} a_{31}\right)\right]
\end{aligned}
$$

Therefore, if $a_{12}>0, a_{45}>0, a_{23} a_{31}>0$ and $a_{46} a_{65}>0$, then 
$a_{45} a_{66}-a_{46} a_{65}<0$ and $a_{12} a_{33}-a_{23} a_{31}<0$.

In this case the sign of $d y_{a}^{g} / d e$ is equal to

$$
L(-)+(-K) a_{15}\left[a_{13}(+)+a_{23}(+)\right]-M(+) .
$$

If $a_{15}=a_{12}=a_{45}$ and $a_{13}=a_{31}=a_{46}=a_{64}=0$, i.e. goods are independent, then the sign of $d y_{a}^{g} / d e$ is equal to

$$
-K a_{15} a_{23}(-)+L(-)-M a_{15}(+) .
$$

(5) The sign of $d y_{b}^{g} / d e$ is equal to

$$
\begin{aligned}
& \left|\begin{array}{cccccc}
a_{11} & a_{12} & a_{13} & 0 & 0 & 0 \\
a_{12} & a_{22} & a_{23} & a_{15} & 0 & 0 \\
a_{31} & a_{32} & a_{33} & 0 & K & 0 \\
0 & a_{15} & 0 & a_{44} & L & a_{46} \\
a_{15} & 0 & 0 & a_{45} & M & a_{56} \\
0 & 0 & 0 & a_{64} & 0 & a_{66}
\end{array}\right|=K\left|\begin{array}{ccccc}
a_{11} & a_{12} & a_{13} & 0 & 0 \\
a_{12} & a_{22} & a_{23} & a_{15} & 0 \\
0 & a_{15} & 0 & a_{44} & a_{46} \\
a_{15} & 0 & 0 & a_{45} & a_{56} \\
0 & 0 & 0 & a_{64} & a_{66}
\end{array}\right| \\
& -L\left|\begin{array}{ccccc}
a_{11} & a_{12} & a_{13} & 0 & 0 \\
a_{12} & a_{22} & a_{23} & a_{15} & 0 \\
a_{31} & a_{32} & a_{33} & 0 & 0 \\
a_{15} & 0 & 0 & a_{45} & a_{56} \\
0 & 0 & 0 & a_{64} & a_{66}
\end{array}\right|+M\left|\begin{array}{ccccc}
a_{11} & a_{12} & a_{13} & 0 & 0 \\
a_{12} & a_{22} & a_{23} & a_{15} & 0 \\
a_{31} & a_{32} & a_{33} & 0 & 0 \\
0 & a_{15} & 0 & a_{44} & a_{46} \\
0 & 0 & 0 & a_{64} & a_{66}
\end{array}\right| \\
& =K\left(a_{13}\left|\begin{array}{cccc}
a_{12} & a_{22} & a_{15} & 0 \\
0 & a_{15} & a_{44} & a_{46} \\
a_{15} & 0 & a_{45} & a_{56} \\
0 & 0 & a_{64} & a_{66}
\end{array}\right|-a_{23}\left|\begin{array}{cccc}
a_{11} & a_{12} & 0 & 0 \\
0 & a_{15} & a_{44} & a_{46} \\
a_{15} & 0 & a_{45} & a_{56} \\
0 & 0 & a_{64} & a_{66}
\end{array}\right|\right) \\
& -L\left(a_{66}\left|\begin{array}{cccc}
a_{11} & a_{12} & a_{13} & 0 \\
a_{12} & a_{22} & a_{23} & a_{15} \\
a_{31} & a_{32} & a_{33} & 0 \\
a_{15} & 0 & 0 & a_{45}
\end{array}\right|-a_{56} a_{64}\left|\begin{array}{ccc}
a_{11} & a_{12} & a_{13} \\
a_{12} & a_{22} & a_{23} \\
a_{31} & a_{32} & a_{33}
\end{array}\right|\right)+M(-) \\
& =K\left[a_{13}\left(a_{12} a_{15}\left|\begin{array}{cc}
a_{45} & a_{56} \\
a_{64} & a_{66}
\end{array}\right|+a_{15}\left|\begin{array}{ccc}
a_{22} & a_{15} & 0 \\
a_{15} & a_{44} & a_{46} \\
0 & a_{64} & a_{66}
\end{array}\right|\right)\right.
\end{aligned}
$$




$$
\begin{aligned}
&\left.-a_{23}\left(a_{11} a_{15}\left|\begin{array}{ll}
a_{45} & a_{56} \\
a_{64} & a_{66}
\end{array}\right|+a_{12} a_{15}\left|\begin{array}{ll}
a_{44} & a_{46} \\
a_{64} & a_{66}
\end{array}\right|\right)\right] \\
&-L\left[a_{66}\left(a_{45}\left|\begin{array}{lll}
a_{11} & a_{12} & a_{13} \\
a_{12} & a_{22} & a_{23} \\
a_{31} & a_{32} & a_{33}
\end{array}\right|+\left(a_{15}\right)^{2}\left|\begin{array}{ll}
a_{12} & a_{13} \\
a_{32} & a_{33}
\end{array}\right|\right)\right. \\
&=K a_{15}\left[\left(a_{13} a_{12}-a_{23} a_{11}\right)\left(a_{45} a_{66}-a_{56} a_{64}\right)-a_{23} a_{12}(+)+a_{13}(-)\right] \\
&-L\left[\left(a_{66} a_{45}-a_{56} a_{64}\right)(-)+a_{66}\left(a_{15}\right)^{2}\left(a_{12} a_{33}-a_{13} a_{32}\right)\right]+M(-) .
\end{aligned}
$$

Therefore, if $a_{12}>0, a_{45}>0, a_{15} \neq 0, a_{13} a_{32}>0$ and $a_{56} a_{64}>0$, then $a_{45} a_{66}-a_{56} a_{64}<0$ and $a_{12} a_{33}-a_{13} a_{32}<0$.

In this case the sign of $d y_{b}^{g} / d e$ is equal to

$$
K a_{15}\left[a_{13}(-)+a_{23}(-)\right]-L(+)-M(+) .
$$

If $a_{15}=a_{12}=a_{45}$ and $a_{13}=a_{31}=a_{46}=a_{64}=0$, i.e. goods are independent, then the sign of $d y_{b}^{g} / d e$ is equal to

$$
-K a_{15}^{2} a_{23}(+)+L a_{15}(-)+M(-) \text {. }
$$

(6) The sign of $d y_{b}^{m} / d e$ is equal to

$$
\begin{gathered}
\left|\begin{array}{cccccc}
a_{11} & a_{12} & a_{13} & 0 & a_{15} & 0 \\
a_{12} & a_{22} & a_{23} & a_{15} & 0 & 0 \\
a_{31} & a_{32} & a_{33} & 0 & 0 & K \\
0 & a_{15} & 0 & a_{44} & a_{45} & L \\
a_{15} & 0 & 0 & a_{45} & a_{55} & M \\
0 & 0 & 0 & a_{64} & a_{65} & 0
\end{array}\right|=-K\left|\begin{array}{ccccc}
a_{11} & a_{12} & a_{13} & 0 & a_{15} \\
a_{12} & a_{22} & a_{23} & a_{15} & 0 \\
0 & a_{15} & 0 & a_{44} & a_{45} \\
a_{15} & 0 & 0 & a_{45} & a_{55} \\
0 & 0 & 0 & a_{64} & a_{65}
\end{array}\right| \\
+L\left|\begin{array}{ccccc}
a_{11} & a_{12} & a_{13} & 0 & a_{15} \\
a_{12} & a_{22} & a_{23} & a_{15} & 0 \\
a_{31} & a_{32} & a_{33} & 0 & 0 \\
a_{15} & 0 & 0 & a_{45} & a_{55} \\
0 & 0 & 0 & a_{64} & a_{65}
\end{array}\right|-M\left|\begin{array}{ccccc}
a_{11} & a_{12} & a_{13} & 0 & a_{15} \\
a_{12} & a_{22} & a_{23} & a_{15} & 0 \\
a_{31} & a_{32} & a_{33} & 0 & 0 \\
0 & a_{15} & 0 & a_{44} & a_{45} \\
0 & 0 & 0 & a_{64} & a_{65}
\end{array}\right|
\end{gathered}
$$




$$
\begin{aligned}
& =-K\left(a_{13}\left|\begin{array}{cccc}
a_{12} & a_{22} & a_{15} & 0 \\
0 & a_{15} & a_{44} & a_{45} \\
a_{15} & 0 & a_{45} & a_{55} \\
0 & 0 & a_{64} & a_{65}
\end{array}\right|-a_{23}\left|\begin{array}{cccc}
a_{11} & a_{12} & 0 & a_{15} \\
0 & a_{15} & a_{44} & a_{45} \\
a_{15} & 0 & a_{45} & a_{55} \\
0 & 0 & a_{64} & a_{65}
\end{array}\right|\right) \\
& +L\left(-a_{64}\left|\begin{array}{cccc}
a_{11} & a_{12} & a_{13} & a_{15} \\
a_{12} & a_{22} & a_{23} & 0 \\
a_{31} & a_{32} & a_{33} & 0 \\
a_{15} & 0 & 0 & a_{55}
\end{array}\right|+a_{65}\left|\begin{array}{cccc}
a_{11} & a_{12} & a_{13} & 0 \\
a_{12} & a_{22} & a_{23} & a_{15} \\
a_{31} & a_{32} & a_{33} & 0 \\
a_{15} & 0 & 0 & a_{45}
\end{array}\right|\right) \\
& -M\left(-a_{64}\left|\begin{array}{cccc}
a_{11} & a_{12} & a_{13} & a_{15} \\
a_{12} & a_{22} & a_{23} & 0 \\
a_{31} & a_{32} & a_{33} & 0 \\
0 & a_{15} & 0 & a_{45}
\end{array}\right|+a_{65}\left|\begin{array}{cccc}
a_{11} & a_{12} & a_{13} & 0 \\
a_{12} & a_{22} & a_{23} & a_{15} \\
a_{31} & a_{32} & a_{33} & 0 \\
0 & a_{15} & 0 & a_{44}
\end{array}\right|\right) \\
& =-K\left[a_{13}\left(a_{12} a_{15}\left|\begin{array}{cc}
a_{45} & a_{55} \\
a_{64} & a_{65}
\end{array}\right|+a_{15}\left|\begin{array}{ccc}
a_{22} & a_{15} & 0 \\
a_{15} & a_{44} & a_{45} \\
0 & a_{64} & a_{65}
\end{array}\right|\right)\right. \\
& \left.-a_{23}\left(a_{12} a_{15}\left|\begin{array}{cc}
a_{44} & a_{45} \\
a_{64} & a_{65}
\end{array}\right|+a_{15}\left|\begin{array}{ccc}
a_{11} & 0 & a_{15} \\
a_{15} & a_{45} & a_{55} \\
0 & a_{64} & a_{65}
\end{array}\right|\right)\right] \\
& +L\left[-a_{64}(+)+a_{65}\left(a_{45}\left|\begin{array}{lll}
a_{11} & a_{12} & a_{13} \\
a_{12} & a_{22} & a_{23} \\
a_{31} & a_{32} & a_{33}
\end{array}\right|+\left(a_{15}\right)^{2}\left|\begin{array}{ll}
a_{12} & a_{13} \\
a_{32} & a_{33}
\end{array}\right|\right)\right] \\
& -M\left[-a_{64}\left(a_{45}\left|\begin{array}{lll}
a_{11} & a_{12} & a_{13} \\
a_{12} & a_{22} & a_{23} \\
a_{31} & a_{32} & a_{33}
\end{array}\right|+\left(a_{15}\right)^{2}\left|\begin{array}{ll}
a_{12} & a_{23} \\
a_{31} & a_{33}
\end{array}\right|\right)+a_{65}(+)\right] \\
& =-K\left(a_{15}\right)\left[a_{13}\left(a_{12}\left|\begin{array}{ll}
a_{45} & a_{55} \\
a_{64} & a_{65}
\end{array}\right|+a_{22}\left|\begin{array}{ll}
a_{44} & a_{45} \\
a_{64} & a_{65}
\end{array}\right|-\left(a_{15}\right)^{2} a_{65}\right)\right. \\
& \left.-a_{23}\left(a_{12}\left|\begin{array}{ll}
a_{44} & a_{45} \\
a_{64} & a_{65}
\end{array}\right|+a_{11}\left|\begin{array}{ll}
a_{45} & a_{55} \\
a_{64} & a_{65}
\end{array}\right|+\left(a_{15}\right)^{2} a_{64}\right)\right] \\
& +L\left[-a_{64}(+)+a_{65} a_{45}(-)+a_{65}\left(a_{15}\right)^{2}\left(a_{12} a_{33}-a_{13} a_{32}\right)\right]
\end{aligned}
$$




$$
\begin{array}{r}
-M\left[-a_{64} a_{45}(-)-a_{64}\left(a_{15}\right)^{2}\left(a_{12} a_{33}-a_{23} a_{31}\right)+a_{65}(+)\right] \\
=-K\left(a_{15}\right)\left[a_{13} a_{12}\left(a_{45} a_{65}-a_{55} a_{64}\right)-a_{23} a_{12}\left(a_{44} a_{65}-a_{45} a_{64}\right)\right. \\
\left.+a_{23} a_{64}\left(a_{11} a_{55}-a_{15}^{2}\right)+a_{13} a_{65}\left(a_{22} a_{44}-a_{15}^{2}\right)\right] \\
+L\left[-a_{64}(+)+a_{65} a_{45}(-)+a_{65}\left(a_{15}\right)^{2}\left(a_{12} a_{33}-a_{13} a_{32}\right)\right] \\
+M\left[a_{64} a_{45}(-)+a_{64}\left(a_{15}\right)^{2}\left(a_{12} a_{33}-a_{23} a_{31}\right)-a_{65}(+)\right]
\end{array}
$$

Therefore, if $a_{12}>0, a_{45}>0$ and $a_{13} a_{32}>0$ and $a_{23} a_{31}>0$, then the sign of $d y_{b}^{m} / d e$ is equal to

$$
\begin{aligned}
& -K a_{15}\left[a_{13}(+)+a_{23}(+)\right]\left[\left(a_{65}(+)+a_{64}(+)\right]\right. \\
& +M\left[a_{64}(-)-a_{65}(+)\right]+L\left[a_{64}(-)+a_{65}(-)\right] .
\end{aligned}
$$

If $a_{15}=a_{12}=a_{45}$ and $a_{13}=a_{31}=a_{46}=a_{64}=0$, i.e. goods are independent, then the sign of $d y_{b}^{m} / d e$ is equal to

$$
-K a_{15}^{2} a_{23} a_{65}+L a_{15} a_{65}(-)+M a_{65}(-) .
$$

(7) If $a_{15}=a_{12}=a_{45}$ and $a_{13}=a_{31}=a_{46}=a_{64}=0$, i.e. goods are independent, then the sign of $d y_{b} / d e=d y_{b}^{g} / d e+d y_{b}^{m} / d e$ is equal to

$$
\begin{aligned}
& \left|\begin{array}{cccccc}
a_{11} & a_{15} & 0 & 0 & 0 & 0 \\
a_{15} & a_{22} & a_{23} & a_{15} & 0 & 0 \\
0 & a_{32} & a_{33} & 0 & K & 0 \\
0 & a_{15} & 0 & a_{44} & L & 0 \\
a_{15} & 0 & 0 & a_{15} & M & a_{56} \\
0 & 0 & 0 & 0 & 0 & a_{66}
\end{array}\right|+\left|\begin{array}{cccccc}
a_{11} & a_{15} & 0 & 0 & a_{15} & 0 \\
a_{15} & a_{22} & a_{23} & a_{15} & 0 & 0 \\
0 & a_{32} & a_{33} & 0 & 0 & K \\
0 & a_{15} & 0 & a_{44} & a_{15} & L \\
a_{15} & 0 & 0 & a_{15} & a_{55} & M \\
0 & 0 & 0 & 0 & a_{65} & 0
\end{array}\right| \\
& =\left(a_{66}-a_{65}\right)\left|\begin{array}{ccccc}
a_{11} & a_{15} & 0 & 0 & 0 \\
a_{15} & a_{22} & a_{23} & a_{15} & 0 \\
0 & a_{32} & a_{33} & 0 & K \\
0 & a_{15} & 0 & a_{44} & L \\
a_{15} & 0 & 0 & a_{15} & M
\end{array}\right| \\
& =\left(a_{66}-a_{65}\right)\left(K\left|\begin{array}{cccc}
a_{11} & a_{15} & 0 & 0 \\
a_{15} & a_{22} & a_{23} & a_{15} \\
0 & a_{15} & 0 & a_{44} \\
a_{15} & 0 & 0 & a_{15}
\end{array}\right|-L\left|\begin{array}{cccc}
a_{11} & a_{15} & 0 & 0 \\
a_{15} & a_{22} & a_{23} & a_{15} \\
0 & a_{32} & a_{33} & 0 \\
a_{15} & 0 & 0 & a_{15}
\end{array}\right|\right.
\end{aligned}
$$




$$
\begin{aligned}
& \left.+M\left|\begin{array}{cccc}
a_{11} & a_{15} & 0 & 0 \\
a_{15} & a_{22} & a_{23} & a_{15} \\
0 & a_{32} & a_{33} & 0 \\
0 & a_{15} & 0 & a_{44}
\end{array}\right|\right) \\
& =\left(a_{66}-a_{65}\right)\left[K a_{15}\left(\left|\begin{array}{ccc}
a_{11} & a_{15} & 0 \\
a_{15} & a_{22} & a_{23} \\
0 & a_{15} & 0
\end{array}\right|-\left|\begin{array}{ccc}
a_{15} & 0 & 0 \\
a_{22} & a_{23} & a_{15} \\
a_{15} & 0 & a_{44}
\end{array}\right|\right)\right. \\
& \left.-L a_{15}\left(\left|\begin{array}{ccc}
a_{11} & a_{15} & 0 \\
a_{15} & a_{22} & a_{23} \\
0 & a_{32} & a_{33}
\end{array}\right|-\left|\begin{array}{ccc}
a_{15} & 0 & 0 \\
a_{22} & a_{23} & a_{15} \\
a_{32} & a_{33} & 0
\end{array}\right|\right)+M(+)\right] \\
& =\left(a_{66}-a_{65}\right)\left\{K a_{15}^{2}\left(-a_{11} a_{23}-a_{44} a_{23}\right)-L a_{15}\left[(-)+a_{33} a_{15}^{2}\right]+M(+)\right\}= \\
& =\left(a_{66}-a_{65}\right)\left[(-) a_{23}+a_{15}(+)+(+)\right] \text {. }
\end{aligned}
$$

We have

$$
a_{66}-a_{65}=\Pi_{g}^{66}-\Pi_{g}^{65}=p_{b y}^{2}<0
$$

and

$$
\operatorname{sign} \frac{d y_{b}}{d e}=(+) a_{23}+(-) a_{15}+(-) .
$$

From equations $(55),(57),(59),(61),(63)$ and (65) we obtain

(a) if $a_{12}, a_{45}>0$ and

- $a_{13}, a_{23}, a_{31}, a_{32}<0$, i.e. both goods are treated as strategic substitutes by both firms in country $x$;

- expressions $a_{46}, a_{56}, a_{64}, a_{65}$ have the same sign, i.e, both goods are treated as strategic complements or as strategic substitutes by both firms in country $y$;

- $a_{15}=-c_{g}^{12}>0$, i.e. firm $g$ has economies of joint production;

then

$$
\operatorname{sign} d x_{a}^{g} / d e=\operatorname{sign} d x_{b}^{g} / d e=\operatorname{sign} d y x_{a}^{g} / d e=\operatorname{sign} d y_{b}^{g} / d e=-,
$$

i.e. firm $g$ sells less of its products in both countries, and $d x_{b}^{m} / d e>0$, i.e. firm $m$ sells more in country $x$. The sign of $d y_{b}^{m} / d e$ depends on the signs of $a_{64}$ and $a_{65}$. If $a_{64}, a_{65}>(<) 0$, i.e. both goods in country $y$ are treated as strategic complements (substitutes) by both firms, then $d y_{b}^{m} / d e<(>) 0$. 
(b) if $a_{12}, a_{45}>0$ and

- $a_{13}, a_{23}, a_{31}, a_{32}>0$, i.e. both goods are treated as strategic complements by both firms in country $x$

- expressions $a_{46}, a_{56}, a_{64}, a_{65}$ have the same sign, i.e. both goods are treated as strategic complements or as strategic substitutes by both firms in country $y$;

- $a_{15}=-c_{g}^{12}<0$, i.e. firm $g$ has diseconomies of joint production;

then

$$
\operatorname{sign} d x_{a}^{g} / d e=\operatorname{sign} d x_{b}^{g} / d e=\operatorname{sign} d x_{b}^{m} / d e=+
$$

and

$$
\operatorname{sign} d y_{a}^{g} / d e=\operatorname{sign} d y_{b}^{g} / d e=-.
$$

The sign of $d y_{b}^{m} / d e$ depends on the signs of $a_{64}$ and $a_{65}$. If $a_{64}, a_{65}>$ $(<) 0$, i.e. both goods in country $y$ are treated as strategic complements (substitutes) by both firms, then $d y_{b}^{m} / d e<(>) 0$.

Proposition 4 follows immediately from (a) and (b).

From equations (56), (58), (60), (62), (64) and (67) one immediately gets proposition 5 .

\subsection{Proof of Proposition 6}

If goods are independent and there are no economies of joint production, matrix $A$ is

$$
\left[\begin{array}{cccccc}
a_{11} & 0 & 0 & a_{14} & 0 & 0 \\
0 & a_{22} & a_{23} & 0 & a_{25} & 0 \\
0 & a_{32} & a_{33} & 0 & 0 & a_{36} \\
a_{14} & 0 & 0 & a_{44} & 0 & 0 \\
0 & a_{25} & 0 & 0 & a_{55} & a_{56} \\
0 & 0 & a_{36} & 0 & a_{65} & a_{66}
\end{array}\right]
$$

and we can decompose the comparative statics system (32) into two systems:

- for $\operatorname{good} a$ :

$$
\left[\begin{array}{ll}
a_{11} & a_{14} \\
a_{14} & a_{44}
\end{array}\right]-\left[\begin{array}{l}
d x_{a}^{g} \\
d y_{a}^{g}
\end{array}\right]=\left[\begin{array}{l}
0 \\
L
\end{array}\right] d e,
$$


- and for good $b$ :

$$
\left[\begin{array}{cccc}
a_{22} & a_{23} & a_{25} & 0 \\
a_{32} & a_{33} & 0 & a_{36} \\
a_{25} & 0 & a_{55} & a_{56} \\
0 & a_{36} & a_{65} & a_{66}
\end{array}\right]\left[\begin{array}{c}
d x_{b}^{g} \\
d x_{b}^{m} \\
d y_{b}^{g} \\
d y_{b}^{m}
\end{array}\right]=\left[\begin{array}{c}
0 \\
K \\
M \\
0
\end{array}\right] d e .
$$

Lemma 1 If products are independent and there are no economies of joint production then

(1) We have $\operatorname{sign} \frac{d x_{a}}{d e}=-\operatorname{sign} a_{14}$.

(2) (a) If $a_{56} a_{65}>0$ and $a_{36} a_{56}<0$ and $a_{23}<0$ and $a_{25}>0$ then $\frac{d x_{b}^{g}}{d e}<0$,

(b) if $a_{56} a_{65}>0$ and $a_{36} a_{56}<0$ and $a_{23}>0$ and $a_{25}<0$ then $\frac{d x_{b}^{g}}{d e}>0$.

(3) If $a_{25} a_{32}<0$ and $a_{36} a_{65}<0$ then $\frac{d x_{b}^{m}}{d e}>0$.

(4) Always $\frac{d y_{a}}{d e}<0$.

(5) If $a_{25} a_{23}<0$ and $a_{36} a_{56}<0$ then $\frac{d y_{b}^{g}}{d e}<0$.

(6) (a) If $a_{23} a_{32}>0$ and $a_{23} a_{25}<0$ and $a_{65}>0$ and $a_{36}<0$ then $\frac{d y_{b}^{m}}{d e}<0$,

(b) if $a_{23} a_{32}>0$ and $a_{23} a_{25}<0$ and $a_{65}<0$ and $a_{36}>0$ then $\frac{d y_{b}^{m}}{d e}>0$.

\section{PROOF.}

(1) By (69) the sign of the $\frac{d x_{a}^{g}}{d e}$ is equal to

$$
-L a_{14}=-a_{14}
$$

(2) By (70) he sign of $\frac{d x_{b}^{g}}{d e}$ is equal to

$$
\begin{gathered}
\left|\begin{array}{cccc}
0 & a_{23} & a_{25} & 0 \\
K & a_{33} & 0 & a_{36} \\
M & 0 & a_{55} & a_{56} \\
0 & a_{36} & a_{65} & a_{66}
\end{array}\right|=-K\left|\begin{array}{ccc}
a_{23} & a_{25} & 0 \\
0 & a_{55} & a_{56} \\
a_{36} & a_{65} & a_{66}
\end{array}\right|+M\left|\begin{array}{ccc}
a_{23} & a_{25} & 0 \\
a_{33} & 0 & a_{36} \\
a_{36} & a_{65} & a_{66}
\end{array}\right| \\
=-K\left(a_{23}\left|\begin{array}{cc}
a_{55} & a_{56} \\
a_{65} & a_{66}
\end{array}\right|+a_{36} a_{25} a_{56}\right)+M\left(-a_{25}\left|\begin{array}{cc}
a_{33} & a_{36} \\
a_{63} & a_{66}
\end{array}\right|-a_{23} a_{36} a_{65}\right) \\
=(-K)\left[\left(a_{23}(+)+a_{36} a_{25} a_{56}\right]+M\left[-a_{25}(+)-a_{23} a_{36} a_{65}\right]\right. \\
=(+) a_{23}+(+) a_{36} a_{25} a_{56}+(-) a_{25}+(-) a_{23} a_{36} a_{65} .
\end{gathered}
$$


(3) From (70) the sign of $\frac{d x_{b}^{m}}{d e}$ is equal to $\left|\begin{array}{cccc}a_{22} & 0 & a_{25} & 0 \\ a_{32} & K & 0 & a_{36} \\ a_{25} & M & a_{55} & a_{56} \\ 0 & 0 & a_{65} & a_{66}\end{array}\right|=K\left|\begin{array}{ccc}a_{22} & a_{25} & 0 \\ a_{25} & a_{55} & a_{56} \\ 0 & a_{65} & a_{66}\end{array}\right|-M\left|\begin{array}{ccc}a_{22} & a_{25} & 0 \\ a_{32} & 0 & a_{36} \\ 0 & a_{65} & a_{66}\end{array}\right|$ $=K(-)-M\left(-a_{22} a_{36} a_{65}-a_{66} a_{32} a_{25}\right)=(+)-\left[a_{36} a_{65}(+)+a_{32} a_{25}(+)\right]$.

(4) By (69) the sign of the $\frac{d y_{a}^{g}}{d e}$ is equal to the sign of

$$
L a_{11}=-
$$

(5) From (70) the sign of $\frac{d y_{b}^{g}}{d e}$ is equal to

$$
\begin{array}{r}
\left|\begin{array}{cccc}
a_{22} & a_{23} & 0 & 0 \\
a_{32} & a_{33} & K & a_{36} \\
a_{25} & 0 & M & a_{56} \\
0 & a_{36} & 0 & a_{66}
\end{array}\right|=-K\left|\begin{array}{ccc}
a_{22} & a_{23} & 0 \\
a_{25} & 0 & a_{56} \\
0 & a_{36} & a_{66}
\end{array}\right|+M\left|\begin{array}{ccc}
a_{22} & a_{23} & 0 \\
a_{32} & a_{33} & a_{36} \\
0 & a_{36} & a_{66}
\end{array}\right| \\
=-K\left(-a_{22} a_{36} a_{56}-a_{66} a_{23} a_{25}\right)+M(-) \\
=a_{36} a_{56}(+)+a_{23} a_{25}(+)+(-) .
\end{array}
$$

(6) From (70 the sign of $\frac{d y_{b}^{m}}{d e}$ is equal to

$$
\begin{gathered}
\left|\begin{array}{cccc}
a_{22} & a_{23} & a_{25} & 0 \\
a_{32} & a_{33} & 0 & K \\
a_{25} & 0 & a_{55} & M \\
0 & a_{36} & a_{65} & 0
\end{array}\right|=K\left|\begin{array}{ccc}
a_{22} & a_{23} & a_{25} \\
a_{25} & 0 & a_{55} \\
0 & a_{36} & a_{65}
\end{array}\right|-M\left|\begin{array}{ccc}
a_{22} & a_{23} & a_{25} \\
a_{32} & a_{33} & 0 \\
0 & a_{36} & a_{65}
\end{array}\right| \\
=K\left(-a_{36}\left|\begin{array}{cc}
a_{22} & a_{25} \\
a_{52} & a_{55}
\end{array}\right|-a_{65} a_{25} a_{23}\right)--M\left(a_{65}\left|\begin{array}{cc}
a_{22} & a_{23} \\
a_{32} & a_{33}
\end{array}\right|\right. \\
\left.+a_{32} a_{25} a_{36}\right)=(+) a_{36}+(+) a_{65} a_{25} a_{23}+(-) a_{65}+(-) a_{32} a_{25} a_{36} .
\end{gathered}
$$

Thus, for Proposition 6, we have

(1) $a_{14}=-c_{g}^{11}>0, a_{25}=-c_{g}^{22}>0, a_{36}=-c_{m}^{\prime \prime}>0$ and

$$
a_{23}=\Pi_{g}^{23}<0, a_{32}=\Pi_{m}^{32}<0, a_{56}=\Pi_{g}^{56}<0, a_{65}=\Pi_{m}^{65}<0 .
$$

From lemma 1 we obtain the result immediately.

(2) $a_{14}=-c_{g}^{11}<0, a_{25}=-c_{g}^{22}<0, a_{36}<0=-c_{m}^{\prime \prime}<0$ and

$$
a_{23}=\Pi_{g}^{23}>0, a_{32}=\Pi_{m}^{32}>0, a_{56}=\Pi_{g}^{56}>0, a_{65}=\Pi_{m}^{65}>0 .
$$

From lemma 1 we obtain the result immediately. 


\section{References}

[1] Bulow, J.I., J.Geanakoplos and P.Klemperer (1985), "Multimarket Oligopoly: Strategic Substitutes and Complements", Journal of Political Economy 93, 488-511.

[2] Delbono, F. and G.Rossini (1992), " Competition Policy vs Horizontal Merger with Public, Entrepreneurial, and LaborManaged Firms", Journal of Comparative Economics, 16, 226-240.

[3] Dixit, A. (1986), "Comparative Statics for Oligopoly", International Economic Review, 27, 107-122.

[4] Dornbusch, R. (1987), "Exchange Rates and Prices", American Economic Review, 27, 93-106.

[5] Hens, T., A.Kirman and L.Phlips (1991), "Exchange Rates and Oligopoly", EUI Working Paper, ECO No. 91/42. European University Institute, Florence.

[6] Kirman, A. and L. Phlips (1992), "Exchange Rate PassThrough and Market Structure", EUI Working Paper, ECO No. 92/83. European University Institute, Florence.

[7] Martin S. and L.Phlips (1994), "Product Differentiation, Market Structure and Exchange Rate Passthrough", in Studies in Industrial Organization, A. von WitTeloostuŸN (ed.), Kluwer Academic Publishers, Dordrecht, 1994. 


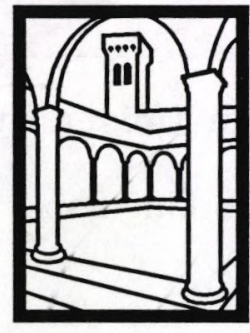

EUI

WORKING

PAPERS

EUI Working Papers are published and distributed by the European University Institute, Florence

Copies can be obtained free of charge

- depending on the availability of stocks - from:

The Publications Officer

European University Institute

Badia Fiesolana

I-50016 San Domenico di Fiesole (FI)

Italy 


\section{国}

\section{Publications of the European University Institute}

Economics Department Working Paper Series

To

Department of Economics WP

European University Institute

Badia Fiesolana

I-50016 San Domenico di Fiesole (FI)

Italy

From Name

Address.

(Please print)

$\square$ Please enter/confirm my name on EUI Economics Dept. Mailing List

$\square$ Please send me a complete list of EUI Working Papers

$\square$ Please send me a complete list of EUI book publications

$\square$ Please send me the EUI brochure Academic Year 1994/95

Please send me the following EUI ECO Working Paper(s):

No, Author

Title:

No, Author

Title:

No, Author

Title:

No, Author

Title:

Date 


\section{Working Papers of the Department of Economics Published since 1993}

ECO No. 93/1

Carlo GRILLENZONI

Forecasting Unstable and Non-Stationary

Time Series

ECO No. 93/2

Carlo GRILLENZONI

Multilinear Models for Nonlinear Time

Series

ECO No. 93/3

Ronald M. HARSTAD/Louis PHLIPS

Futures Market Contracting When You

Don't Know Who the Optimists Are

ECO No. 93/4

Alan KIRMAN/Louis PHLIPS

Empirical Studies of Product Markets

ECO No. 93/5

Grayham E. MIZON

Empirical Analysis of Time Series:

Illustrations with Simulated Data

ECO No. 93/6

Tilman EHRBECK

Optimally Combining Individual

Forecasts From Panel Data

ECO NO. 93/7

Víctor GÓMEZ/Agustín MARAVALL Initializing the Kalman Filter with Incompletely Specified Initial Conditions

ECO No. 93/8

Frederic PALOMINO

Informed Speculation: Small Markets

Against Large Markets

ECO NO. 93/9

Stephen MARTIN

Beyond Prices Versus Quantities

ECO No. 93/10

José María LABEAGA/Angel LÓPEZ

A Flexible Demand System and VAT

Simulations from Spanish Microdata

ECO No. 93/11

Maozu LU/Grayham E. MIZON

The Encompassing Principle and

Specification Tests
ECO No. 93/12

Louis PHLIPS/Peter MØLLGAARD

Oil Stocks as a Squeeze Preventing

Mechanism: Is Self-Regulation Possible?

ECO No. 93/13

Pieter HASEKAMP

Disinflation Policy and Credibility: The

Role of Conventions

ECO No. 93/14

Louis PHLIPS

Price Leadership and Conscious

Parallelism: A Survey

ECO No. 93/15

Agustín MARAVALL

Short-Term Analysis of Macroeconomic

Time Series

ECO No. 93/16

Philip Hans FRANSES/Niels

HALDRUP

The Effects of Additive Outliers on Tests for Unit Roots and Cointegration

\section{ECO No. 93/17}

Fabio CANOVA/Jane MARRINAN

Predicting Excess Returns in Financial

Markets

\section{ECO No. 93/18}

Iñigo HERGUERA

Exchange Rate Fluctuations, Market

Structure and the Pass-through

Relationship

ECO No. 93/19

Agustín MARAVALL

Use and Misuse of Unobserved

Components in Economic Forecasting

ECO No. 93/20

Torben HOLVAD/Jens Leth

HOUGAARD

Measuring Technical Input Efficiency for Similar Production Units:

A Survey of the Non-Parametric

Approach 
ECO No. 93/21

Stephen MARTIN/Louis PHLIPS

Product Differentiation, Market Structure and Exchange Rate Passthrough

ECO No 93/22

F. CANOVA/M. FINN/A. R. PAGAN

Evaluating a Real Business Cycle Model

ECO No 93/23

Fabio CANOVA

Statistical Inference in Calibrated Models

ECO No 93/24

Gilles TEYSSIÈRE

Matching Processes in the Labour Market in Marseilles. An Econometric Study

\section{ECO No 93/25}

Fabio CANOVA

Sources and Propagation of International

Business Cycles: Common Shocks or

Transmission?

ECO No. 93/26

Marco BECHT/Carlos RAMÍREZ

Financial Capitalism in Pre-World War I

Germany: The Role of the Universal

Banks in the Financing of German

Mining Companies 1906-1912

ECO No. 93/27

Isabelle MARET

Two Parametric Models of Demand,

Structure of Market Demand from

Heterogeneity

ECO No. 93/28

Stephen MARTIN

Vertical Product Differentiation, Intra-

industry Trade, and Infant Industry

Protection

ECO No. 93/29

J. Humberto LOPEZ

Testing for Unit Roots with the k-th

Autocorrelation Coefficient

ECO No. 93/30

Paola VALBONESI

Modelling Interactions Between State and

Private Sector in a "Previously" Centrally

Planned Economy
ECO No. 93/31

Enrique ALBEROLA ILA/J. Humberto LOPEZ/Vicente ORTS RIOS

An Application of the Kalman Filter to the Spanish Experience in a Target Zone (1989-92)

ECO No. 93/32

Fabio CANOVA/Morten O. RAVN

International Consumption Risk Sharing

ECO No. 93/33

Morten Overgaard RAVN

International Business Cycles: How much can Standard Theory Account for?

ECO No. 93/34

Agustín MARAVALL

Unobserved Components in Economic

Time Series

ECO No. 93/35

Sheila MARNIE/John

MICKLEWRIGHT

"Poverty in Pre-Reform Uzbekistan:

What do Official Data Really Reveal?"

ECO No. 93/36

Torben HOLVAD/Jens Leth

HOUGAARD

Measuring Technical Input Efficiency for

Similar Production Units:

80 Danish Hospitals

ECO No. 93/37

Grayham E. MIZON

A Simple Message for Autocorrelation Correctors: DON'T

ECO No. 93/38

Barbara BOEHNLEIN

The Impact of Product Differentiation on Collusive Equilibria and Multimarket Contact

ECO No. 93/39

H. Peter MØLLGAARD

Bargaining and Efficiency in a

Speculative Forward Market

潘棌 
ECO No. 94/1

Robert WALDMANN

Cooperatives With Privately Optimal

Price Indexed Debt Increase Membership

When Demand Increases

ECO No. 94/2

Tilman EHRBECK/Robert

WALDMANN

Can Forecasters' Motives Explain

Rejection of the Rational Expectations

Hypothesis?

ECO No. $94 / 3$

Alessandra PELLONI

Public Policy in a Two Sector Model of

Endogenous Growth

ECO No. 94/4

David F. HENDRY

On the Interactions of Unit Roots and

Exogeneity

ECO No. 94/5

Bernadette GOVAERTS/David F.

HENDRY/Jean-François RICHARD

Encompassing in Stationary Linear

Dynamic Models

ECO No. 94/6

Luigi ERMINI/Dongkoo CHANG

Testing the Joint Hypothesis of Rationality and Neutrality under Seasonal Cointegration: The Case of Korea

ECO No. 94/7

Gabriele FIORENTINI/Agustín

MARAVALL

Unobserved Components in ARCH

Models: An Application to Seasonal

Adjustment

ECO No. 94/8

Niels HALDRUP/Mark SALMON

Polynomially Cointegrated Systems and their Representations: A Synthesis

ECO No. 94/9

Mariusz TAMBORSKI

Currency Option Pricing with Stochastic

Interest Rates and Transaction Costs:

A Theoretical Model

ECO No. 94/10

Mariusz TAMBORSKI

Are Standard Deviations Implied in

Currency Option Prices Good Predictors

of Future Exchange Rate Volatility?
ECO No. 94/11

John MICKLEWRIGHT/Gyula NAGY

How Does the Hungarian Unemploy-

ment Insurance System Really Work?

ECO No. 94/12

Frank CRITCHLEY/Paul

MARRIOTT/Mark SALMON

An Elementary Account of Amari's

Expected Geometry

ECO No. 94/13

Domenico Junior MARCHETTI

Procyclical Productivity, Externalities and Labor Hoarding: A Reexamination of Evidence from U.S. Manufacturing

ECO No. 94/14

Giovanni NERO

A Structural Model of Intra-European

Airline Competition

ECO No. 94/15

Stephen MARTIN

Oligopoly Limit Pricing: Strategic

Substitutes, Strategic Complements

ECO No. 94/16

Ed HOPKINS

Learning and Evolution in a

Heterogeneous Population

ECO No. 94/17

Berthold HERRENDORF

Seigniorage, Optimal Taxation, and Time

Consistency: A Review

ECO No. 94/18

Frederic PALOMINO

Noise Trading in Small Markets

ECO No. 94/19

Alexander SCHRADER

Vertical Foreclosure, Tax Spinning and

Oil Taxation in Oligopoly

ECO No. 94/20

Andrzej BANIAK/Louis PHLIPS

La Pléiade and Exchange Rate Pass-

Through 


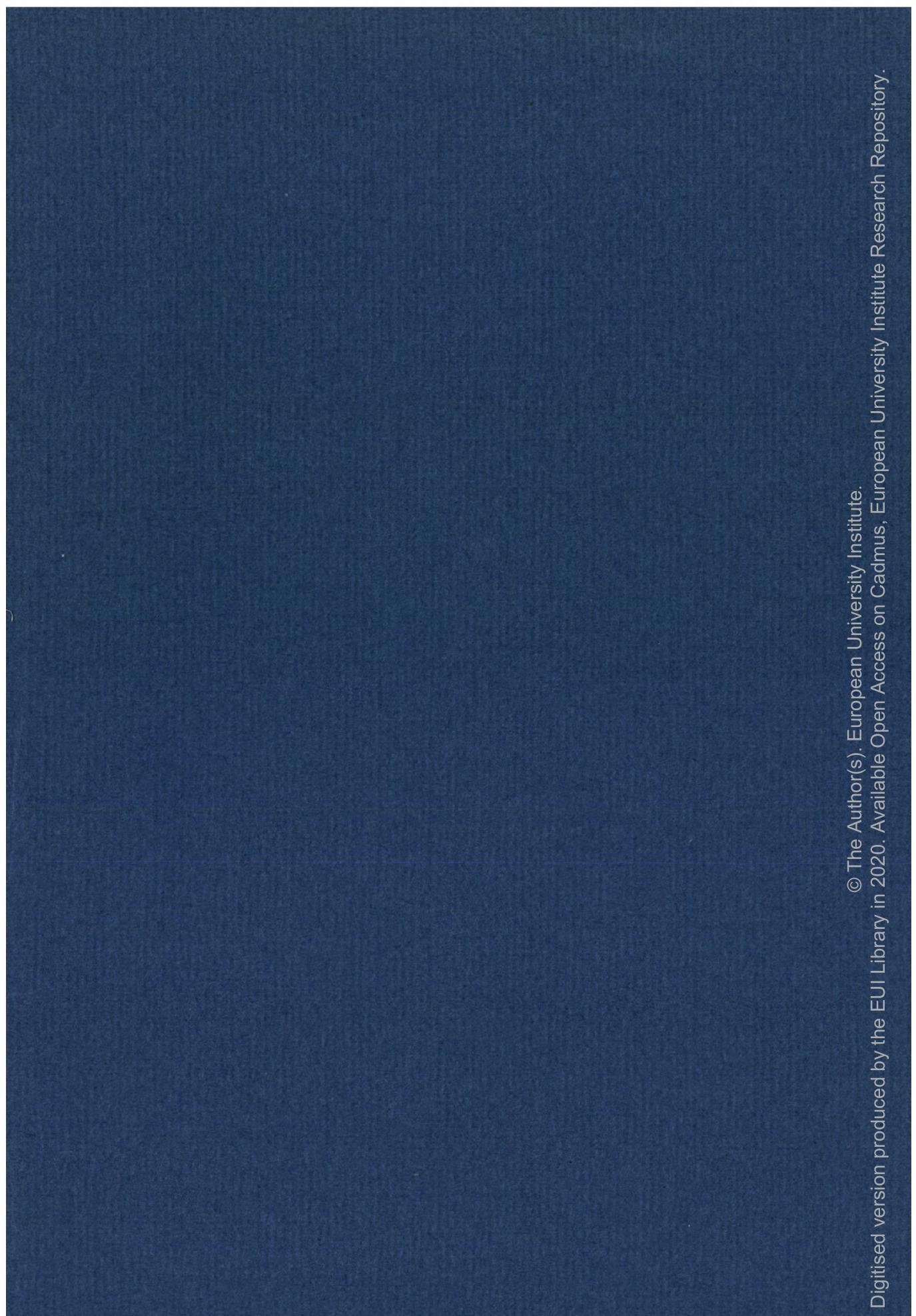




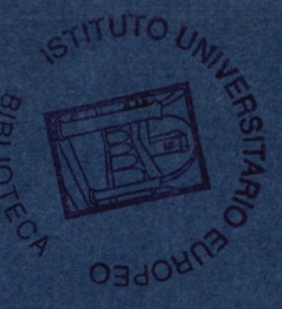

$\stackrel{\oplus}{\frac{1}{3}}$ 